\title{
Hybrid iterative algorithm for an infinite families of closed, uniformly asymptotic regular and uniformly Bregman totally quasi- $D$-asymptotically nonexpansive mappings in Banach spaces
}

\section{Renxing Ni}

Department of Mathematics, Shaoxing University, Zhejiang, 312000, China.

Communicated by Y. Yao

\begin{abstract}
A new hybrid Bregman projection method is considered for finding common solutions of the set of common fixed points of an infinite family of closed, uniformly asymptotic regular and uniformly Bregman totally quasi- $D$-asymptotically nonexpansive mappings, the set of solutions to a variational inequality problem and the set of common solutions to a system of generalized mixed equilibrium problems, strong convergence theorems of common elements are proved by using new analysis techniques and Bregman mappings in the setting of uniformly smooth and 2-uniformly convex real Banach spaces. Our results improve and generalize many important known recent results in the current literature, because Bregman projection mapping generalizes the generalized projection mapping and the metric projection mapping. (c)2016 All rights reserved.
\end{abstract}

Keywords: Hybrid Bregman projection method, Bregman totally quasi- $D$-asymptotically nonexpansive mapping, variational inequality problem, generalized mixed equilibrium problem, uniformly smooth Banach space, 2-uniformly convex Banach space.

2010 MSC: 47J20, 47H09, 47H10.

\section{Introduction}

Let $E$ be a real Banach space with the dual $E^{*}, C$ be a nonempty closed convex subset of $E, f$ be a bifunction from $C \times C$ to $R, \varphi: C \rightarrow R$ be a real-valued function and $A: C \rightarrow E^{*}$ be a nonlinear mapping.

Email address: nrx1964@163.com (Renxing Ni) 
The so-called generalized mixed equilibrium problem [33, 34] is to find $z \in C$ such that

$$
f(z, y)+\langle A z, y-z\rangle+\varphi(y)-\varphi(z) \geq 0, \forall y \in C .
$$

The set of solutions of 1.1 is denoted by $\operatorname{GMEP}(f, \varphi)$, that is,

$$
G M E P(f, \varphi)=\{z \in C \mid f(z, y)+\langle A z, y-z\rangle+\varphi(y)-\varphi(z) \geq 0, \forall y \in C\} .
$$

Special cases:

(I) If $A=0$, then the problem (1.1) reduces into the mixed equilibrium problem for $f$, denoted by $\operatorname{MEP}(f, \varphi)$, which is to find $z \in C$ such that

$$
f(z, y)+\varphi(y)-\varphi(z) \geq 0, \forall y \in C .
$$

(II) If $f=0$, then the problem (1.1) reduces into the mixed variational inequality of Browder-type, denoted by $\operatorname{VI}(C, A, \varphi)$, which is to find $z \in C$ such that

$$
\langle A z, y-z\rangle+\varphi(y)-\varphi(z) \geq 0, \forall y \in C .
$$

In particular, $V I(C, A, 0)$ is denoted by $V I(C, A)$.

(III) If $\varphi=0$, then the problem (1.1) reduces into the generalized equilibrium problem, denoted by $G E P(f)$, which is to find $z \in C$ such that

$$
f(z, y)+\langle A z, y-z\rangle \geq 0, \forall y \in C .
$$

(IV) If $A=0, \varphi=0$, then the problem (1.1) reduces into the equilibrium problem, denoted by $E P(f)$, which is to find $z \in C$ such that

$$
f(z, y) \geq 0, \forall y \in C .
$$

The generalized mixed equilibrium problems include fixed point problems, variational inequality problems, optimization problems, equilibrium problems and Nash equilibrium problems as special cases (see for example [33, 34]). Some methods have been proposed to solve the generalized mixed equilibrium problem (see for example [3, 11-16, 18, 20, 26, 27, 33, 34, 36, 38, 43, 47]). Numerous problems in physics, economics and optimization help to find a solution of problem (1.2).

An operator $B: C \rightarrow E^{*}$ is called $\alpha$-inverse-strongly monotone, if there exists a positive real number $\alpha$ such that

$$
\langle x-y, B x-B y\rangle \geq \alpha\|B x-B y\|^{2} \quad \forall x, y \in C .
$$

Obviously, if $B$ is $\alpha$-inverse-strongly monotone, then $B$ is $\frac{1}{\alpha}$-continuous and $V I(C, B)$ is both closed and convex. In this paper, we shall assume that $\left(B_{1}\right) V I(C, B) \neq \emptyset ;\left(B_{2}\right)\|B y\| \leq\|B y-B u\|$ for all $y \in C$ and $u \in V I(C, B)$.

In the sequel, let $F(T)$ denote the set of fixed points of a mapping $T: C \rightarrow C, R^{+}$and $R$ denote the set of all nonnegative real numbers and all real numbers, respectively. A mapping $T: C \rightarrow C$ is said to be nonexpansive, if $\|T x-T y\| \leq\|x-y\|$ for all $x, y \in C$. T is said to be quasi-nonexpansive, if $F(T) \neq \emptyset$ and $\|T x-p\| \leq\|x-p\|$ for all $x \in C, p \in F(T)$.

It turns out that the fixed point theory of nonexpansive mappings can be applied to the solutions of diverse problems such as finding zeros of monotone mappings and solutions to certain evolution equations and solving convex feasibility, variational inequality and equilibrium problems. There are, in fact, many papers that deal with methods for finding fixed points of nonexpansive and quasi-nonexpansive mappings in Hilbert, uniformly convex and uniformly smooth Banach spaces (see for example [3, 11,16, 18, 20, 26, 27, 36, 3843, 47]). 
The main purpose of introducing the concept of relatively nonexpansive mapping is to hope that the results of iterative approximation of relevant nonexpansive mapping in a Hilbert space can be generalized to general Banach space, because, in a Hilbert space $H$, nonexpansive mapping is equivalent to relatively nonexpansive mapping.

Many problems in nonlinear analysis can be reformulated as a problem of finding a fixed point of a nonexpansive mapping $T$ of a closed and convex subset $C$ of a Banach space $E$. In 1953, Mann [16] introduced the following iterative method: a sequence $\left\{x_{n}\right\}$ defined by $x_{1} \in C$ and

$$
x_{n+1}=\alpha_{n} x_{n}+\left(1-\alpha_{n}\right) T x_{n}, \quad n=1,2,3, \cdots,
$$

where $\left\{\alpha_{n}\right\}$ is a sequence in $[0,1]$. It is known that under appropriate conditions the sequence $\left\{x_{n}\right\}$ converges only weakly to a fixed point of $T$. However, even in a Hilbert space, Mann iteration may fail to converge strongly.

Several attempts to construct the iteration method guaranteeing the strong convergence have been made. For example, Halpern [12] proposed the following so-called Halpern iteration:

$$
x_{1}=x \in C \text { and } x_{n+1}=\alpha_{n} x_{1}+\left(1-\alpha_{n}\right) T x_{n}, \quad n=1,2,3, \cdots,
$$

where $\left\{\alpha_{n}\right\}$ is a sequence in $(0,1)$ satisfying

(C1) $\lim _{n \rightarrow+\infty} \alpha_{n}=0$;

(C2) $\Sigma_{n=1}^{+\infty} \alpha_{n}=+\infty$;

(C3) $\lim _{n \rightarrow+\infty} \frac{\alpha_{n}}{\alpha_{n+1}}=1$ or $\Sigma_{n=1}^{+\infty}\left|\alpha_{n}-\alpha_{n+1}\right|<+\infty$.

In 2001, another approach which is the so-called $C Q$ method for a nonexpansive mapping in a Hilbert space $H$ was proposed by Bauschke and Combettes [3. More precisely, their algorithm is defined by

$$
\left\{\begin{array}{l}
x_{1} \in C \text { is arbitrary } \\
y_{n}=\alpha_{n} x_{n}+\left(1-\alpha_{n}\right) T x_{n} \\
C_{n}=\left\{z \in C:\left\|y_{n}-z\right\| \leq\left\|x_{n}-z\right\|\right\} \\
Q_{n}=\left\{z \in C:\left\langle x_{n}-z, x_{1}-x_{n}\right\rangle \geq 0\right\} \\
x_{n+1}=P_{C_{n} \cap Q_{n}} x_{1}, \quad n=1,2,3, \cdots
\end{array}\right.
$$

where $\lim _{n \rightarrow+\infty} \sup \alpha_{n}<1, K$ is a closed and convex subset of $H$, and $P_{K}$ denotes the metric projection from a Hilbert space $H$ onto $K$.

Recently, Martinez-Yanes and Xu [18] has adapted Bauschke and Combettes [3] idea to modify above process for a single nonexpansive mapping $T$ in a Hilbert space $H$ :

$$
\left\{\begin{array}{l}
x_{1} \in C \text { is arbitrary, } \\
y_{n}=\alpha_{n} x_{n}+\left(1-\alpha_{n}\right) T x_{n}, \\
C_{n}=\left\{z \in C:\left\|y_{n}-z\right\|^{2} \leq\left\|x_{n}-z\right\|^{2}+\alpha_{n}\left(\left\|x_{0}\right\|^{2}+2\left\langle x_{n}-x_{0}, z\right\rangle\right)\right\} \\
Q_{n}=\left\{z \in C:\left\langle x_{n}-z, x_{0}-x_{n}\right\rangle \geq 0\right\} \\
x_{n+1}=P_{C_{n} \cap Q_{n}} x_{0}, \quad n=1,2,3, \cdots .
\end{array}\right.
$$

They proved that the sequence $\left\{x_{n}\right\}$ generated by above iterative scheme converges strongly to $P_{F(T)} x_{0}$ provided the sequence $\left\{\alpha_{n}\right\} \subset(0,1)$ satisfies $\lim _{n \rightarrow+\infty} \alpha_{n}=0$.

It should be noted here that the above iteration works only in Hilbert space setting. To extend this iteration to a Banach space, a relatively nonexpansive mapping [3, 12, 18, was introduced. In a Hilbert space $H$, the duality mapping $J$ is the identity mapping and $\phi(x, y)=\|x-y\|^{2}$ for all $x, y \in H$, hence the nonexpansive mapping of $H$ is equivalent to relatively nonexpansive mapping. 
There are many methods for approximating fixed points of relatively nonexpansive mappings (see, e.g., [19, 20, 27, 36]) in a Banach space. Iiduka and Takahashi [13] investigated the following iterative scheme for finding a zero point of a monotone operator $B$ in a uniformly smooth and 2-uniformly convex Banach space $E$ :

$$
\left\{\begin{array}{l}
x_{1} \in E \text { chosen arbitrarily, } \\
y_{n}=J^{-1}\left(J x_{n}-\lambda_{n} B x_{n}\right), \\
C_{n}=\left\{z \in E: \phi\left(z, y_{n}\right) \leq \phi\left(z, x_{n}\right)\right\} \\
Q_{n}=\left\{z \in E:\left\langle x_{n}-z, J x_{1}-J x_{n}\right\rangle \geq 0\right\} \\
x_{n+1}=\Pi_{C_{n} \cap Q_{n}} x_{1},
\end{array}\right.
$$

where $\Pi_{C_{n}} \cap Q_{n}$ is the generalized projection from $E$ onto $C_{n} \bigcap Q_{n}$ and $\left\{\lambda_{n}\right\}$ is a sequence of positive real numbers. They proved that the sequence $\left\{x_{n}\right\}$ converges strongly to an element of $B^{-1}(0)$. Moreover, under the additional suitable assumptions, they proved that the sequence $\left\{x_{n}\right\}$ generated by (1.3) converges strongly to an element of $V I(C, B)$. Some solution methods have been proposed to solve the variational inequality problem, (see for instance, [11, 13, 15, 26, 36, 38, 43, 47]).

In 1967, Bregman [6] discovered a technique for using of the Bregman distance function $D(\cdot, \cdot)$ (see, Section 2, Definition 2.1) in designing and analyzing optimization and feasibility algorithms. Bregman's technique has been applied in various ways. In 2005, Butnariu and Resmerita [7] introduced Bregman-type iterative algorithms and investigated the convergence of the iterative algorithm of solving some nonlinear operator equations.

In 2011, Reich and Sabach [31] introduced the concept of Bregman strongly nonexpansive mapping and study the convergence of two iterative algorithms for finding common fixed points of finitely many Bregman strongly nonexpansive mappings in reflexive Banach spaces. In 2012, Suantai et al. [35] also considered the strong convergence for Bregman strongly nonexpansive mappings in reflexive Banach spaces.

In 2013, Zhu et al. [46] introduced the following hybrid projection algorithm:

$$
\left\{\begin{array}{l}
x_{0} \in C \text { chosen arbitrarily, } \\
C_{1}=C, x_{1}=\operatorname{Proj}_{C_{1}}^{g} x_{0}, \\
y_{n}=\nabla g^{*}\left[\alpha_{n} \nabla g\left(x_{n}\right)+\left(1-\alpha_{n}\right) \nabla g\left(T x_{n}\right)\right], \\
f\left(u_{n}, y\right)+\left\langle y-u_{n}, \nabla g\left(u_{n}\right)-\nabla g\left(y_{n}\right)\right\rangle \geq 0, \forall y \in C, \\
C_{n+1}=\left\{z \in C_{n}: D\left(z, u_{n}\right) \leq D\left(z, x_{n}\right)\right\}, \\
x_{n+1}=\operatorname{Proj}_{C_{n+1}}^{g} x_{0}
\end{array}\right.
$$

for every $n \geq 0$, where $T$ is Bregman strongly nonexpansive mapping. They proved under the appropriate conditions on the parameters that the sequence $\left\{x_{n}\right\}$ generated by 1.4 converges strongly to a common solution of the set of fixed points of Bregman strongly nonexpansive mappings $T$ and the set of solutions of an equilibrium problem $E P(f)$ in a reflexive Banach space $E$, where $\operatorname{Proj}_{F}^{g}\left(x_{0}\right)$ is the Bregman projection of $E$ onto $F$.

Recently, Naraghirad and Yao 22] presented the following Bregman projection proximal algorithm:

$$
\left\{\begin{array}{l}
x_{0} \in C \text { chosen arbitrarily, } \\
C_{0}=C, \\
y_{n}=\operatorname{Proj}_{C}^{g}\left(\nabla g^{*}\left[\nabla g\left(x_{n}\right)-\lambda_{n} B x_{n}\right]\right), \\
z_{n}=\nabla g^{*}\left[\alpha_{n, 0} \nabla g\left(x_{n}\right)+\sum_{i=1}^{\infty} \alpha_{n, i} \nabla g\left(T_{i} y_{n}\right)\right], \\
u_{n} \in C \text { such that } f\left(u_{n}, y\right)+\frac{1}{r_{n}}\left\langle y-u_{n}, \nabla g\left(u_{n}\right)-\nabla g\left(y_{n}\right)\right\rangle \geq 0, \forall y \in C, \\
C_{n+1}=\left\{z \in C_{n}: D\left(z, u_{n}\right) \leq D\left(z, x_{n}\right)\right\}, \\
x_{n+1}=\operatorname{Proj}_{C_{n+1}}^{g} x_{0} .
\end{array}\right.
$$


They proved under the appropriate conditions on the parameters that the sequence $\left\{x_{n}\right\}$ generated by 1.5 converges strongly to a common solution of the set of solutions of an equilibrium problem $E P(f)$, the set of zero points of $\alpha$-inverse strongly monotone mapping $B: C \rightarrow E^{*}$ and the set of fixed points of an infinite family of Bregman weak relatively nonexpansive mappings in a 2-uniformly convex Banach space $E$.

Motivated by the above mentioned results and the on-going research, we introduce a new hybrid Bregman projection algorithm based on the shrinking projection method and prove strong convergence theorems for approximation of a common element of the set of common fixed points of an infinite family of Bregman totally quasi- $D$-asymptotically nonexpansive mappings (which contains Bregman strongly nonexpansive mapping, Bregman relatively nonexpansive mapping, Bregman quasi- $D$-asymptotically nonexpansive mapping in the intermediate sense, Bregman quasi- $D$-nonexpansive mapping, and quasi- $\phi$-asymptotically nonexpansive mapping as its special case), the set of solutions to a variational inequality problem and the set of solutions to a system of generalized mixed equilibrium problems in a 2-uniformly convex real Banach space. The assumption $\widehat{F}(T)=F(T)$ or $\widetilde{F}(T)=F(T)$ on the mapping $T$ is removed. Our results extend the results of Saewan and Kumam [33], Martinez-Yanes and Xu [18], Qin and Su [27], Iiduka and Takahashi [14, Reich and Sabach [28], Naraghirad and Yao [22], Zhu et al. [46], Pang and Naraghirad [24], Chang et al. [9], Agarwal et al. [1], Wu and Lv [37, and many other recent and important results in the literature.

\section{Preliminaries}

Throughout this paper, we denote by $N$ the set of nonnegative integers. Let $E$ be a real Banach space with the dual $E^{*}$. For all $x \in E$ and $x^{*} \in E^{*}$, we denote the value of $x^{*}$ at $x$ by $\left\langle x, x^{*}\right\rangle$. The duality mapping $J: E \rightarrow 2^{E^{*}}$ is defined by $J(x)=\left\{x^{*} \in E^{*}:\left\langle x, x^{*}\right\rangle=\|x\|^{2}=\left\|x^{*}\right\|^{2}\right\}$. Let $g: E \rightarrow$ $R \bigcup\{+\infty\}$ be a proper, convex and lower semicontinuous function. Denote the domain of $g$ by dom $g$ i.e., $\operatorname{dom} g=\{x \in E: g(x)<+\infty\}$. The Fenchel conjugate of $g$ is the function $g^{*}: E^{*} \rightarrow(-\infty,+\infty]$ defined by $g^{*}(\zeta)=\sup _{x \in E}\{\langle\zeta, x\rangle-g(x)\}$. If $E$ is reflexive, we know from [4] that $(\nabla g)^{-1}=\nabla g^{*}, \nabla g=\left(\nabla g^{*}\right)^{-1}$, $\operatorname{ran} \nabla g=\operatorname{dom} \nabla g^{*}=\operatorname{int}\left(\operatorname{dom} g^{*}\right)$ and $\operatorname{ran} \nabla g^{*}=\operatorname{dom} \nabla g=\operatorname{int}(\operatorname{dom} g)$.

Definition 2.1 ([6, 7]). Let $g: E \rightarrow R$ be a Gâteaux differentiable and convex function. The function $D(\cdot, \cdot): \operatorname{dom} g \times \operatorname{int}(\operatorname{dom} g) \rightarrow[0,+\infty)$ defined by $D(y, x)=g(y)-g(x)-\langle y-x, \nabla g(x)\rangle$ is called the Bregman distance with respect to $g$.

It follows from the strict convexity of $g$ that $D(x, y) \geq 0$ for all $x, y$ in $E$. However, $D(\cdot, \cdot)$ might not be symmetric and $D(\cdot, \cdot)$ might not satisfy the triangular inequality.

Remark 2.2 ([31]). The Bregman distance has the following properties:

(1) the three point identity, for any $x \in \operatorname{dom} g$ and $y, z \in \operatorname{int}(\operatorname{dom} g)$,

$$
D(x, z)=D(x, y)+D(y, z)+\langle\nabla g(y)-\nabla g(z), x-y\rangle ;
$$

(2) the four point identity, for any $y, w \in \operatorname{dom} g$ and $x, z \in \operatorname{int}(\operatorname{dom} g)$,

$$
D(y, x)-D(y, z)-D(w, x)+D(w, z)=\langle\nabla g(z)-\nabla g(x), y-w\rangle .
$$

Definition 2.3 ([21]). Let $g: E \rightarrow R$ be a Gâteaux differentiable and convex function, $C$ be the nonempty, closed and convex subset of $E$. The Bregman projection of $x \in \operatorname{int}(\operatorname{dom} g)$ onto $C(\subseteq$ dom $g)$ is the necessarily unique vector $\operatorname{Proj}_{C}^{g}(x) \in C$ satisfying the following:

$$
D\left(\operatorname{Proj}_{C}^{g}(x), x\right)=\inf \{D(y, x): y \in C\} .
$$




\section{Remark 2.4.}

(1) If $E$ is a smooth Banach space and $g(x)=\|x\|^{2}$ for all $x \in E$, then we have that $\nabla g(x)=2 J x$ for all $x$ in $E$. Hence, $D(\cdot, \cdot)$ is reduced to the usual map $\phi(\cdot, \cdot)$ as $D(x, y)=\|x\|^{2}-2\langle x, J y\rangle+\|y\|^{2}=\phi(x, y)$ for all $x, y \in E$. The Bregman projection $\operatorname{Proj}_{C}^{g}(x)$ is reduced to the generalized projection $\Pi_{C}(x)$ (see [6-16]), which is defined by

$$
\phi\left(\Pi_{C}(x), x\right)=\inf \{\phi(y, x): y \in C\},
$$

where $\phi: E \times E \rightarrow R^{+}$denotes the Lyapunov functional defined by $\phi(x, y)=\|x\|^{2}-2\langle x, J y\rangle+\|y\|^{2}$ for all $x, y \in E$. From the definition of $\phi$, we have $(\|x\|-\|y\|)^{2} \leq \phi(x, y) \leq(\|x\|+\|y\|)^{2}$.

(2) If $E$ is a Hilbert space and $g(x)=\|x\|^{2}$ for all $x \in E$, then $D(x, y)=\|x-y\|^{2}$, the Bregman projection $\operatorname{Proj}_{C}^{g}(x)$ is reduced to the metric projection $P_{C}(x)$ of $x$ onto $C$. For more details we refer the readers to [5].

Definition 2.5 ([28]). Let $B$ be the closed unit ball of a Banach space $E$. A function $g: E \rightarrow R$ is said to be

(1) uniformly smooth on bounded subsets of $E$ if the function $\sigma_{r}:[0,+\infty) \rightarrow[0,+\infty]$, defined by

$$
\sigma_{r}(t)=\sup _{x \in r B, y \in E,\|y\|=1, \alpha \in(0,1)}[\alpha g(x+(1-\alpha) t y)+(1-\alpha) g(x-\alpha t y)-g(x)] \times[\alpha(1-\alpha)]^{-1 / 2},
$$

satisfies $\lim _{t \downarrow 0} \frac{\sigma_{r}(t)}{t}=0$ for all $r>0$;

(2) uniformly convex on bounded subsets of $E$ if the gauge $\rho_{r}:[0,+\infty) \rightarrow[0,+\infty]$ of uniform convexity of $g$, defined by

$$
\rho_{r}(t)=\inf _{x, y \in r B,\|x-y\|=t, \alpha \in(0,1)}[\alpha g(x)+(1-\alpha) g(y)-g(\alpha x+(1-\alpha) y)] \times[\alpha(1-\alpha)]^{-1 / 2},
$$

satisfies $\rho_{r}(t)>0$ for all $r, t>0$.

\section{Definition 2.6.}

(1) A mapping $T: C \rightarrow C$ is said to be Bregman totally quasi- $D$-asymptotically nonexpansive [9], if $F(T) \neq \emptyset$ and there exist nonnegative real sequences $\left\{\nu_{n}\right\},\left\{\mu_{n}\right\}$ satisfying $\nu_{n}, \mu_{n} \rightarrow 0($ as $n \rightarrow+\infty)$ and a strictly increasing continuous function $\zeta: R^{+} \rightarrow R^{+}$with $\zeta(0)=0$ such that

$$
D\left(p, T^{n} x\right) \leq D(p, x)+\nu_{n} \cdot \zeta[D(p, x)]+\mu_{n} \forall n \geq 1, x \in C, p \in F(T) .
$$

(2) A mapping $T: C \rightarrow C$ is said to be Bregman quasi- $D$-asymptotically nonexpansive [9], if $F(T) \neq \emptyset$ and there exists a sequence $\left\{k_{n}\right\} \subset[1,+\infty)$ satisfying $\lim _{n \rightarrow+\infty} k_{n}=1$ such that

$$
D\left(p, T^{n} x\right) \leq k_{n} D(p, x) \text { for all } x \in C, p \in F(T) \text { and } n \geq 1 \text {. }
$$

(3) A mapping $T: C \rightarrow C$ is said to be Bregman quasi- $D$-asymptotically nonexpansive in the intermediate sense with sequence $\left\{\nu_{n}\right\}$ [23], if $F(T) \neq \emptyset$ and there exists a sequence $\left\{\nu_{n}\right\}$ in $[0,+\infty)$ satisfying $\lim _{n \rightarrow+\infty} \nu_{n}=0$ such that

$$
\limsup _{n \rightarrow+\infty} \sup _{x \in C, p \in F(T)}\left[D\left(p, T^{n} x\right)-\left(1+\nu_{n}\right) D(p, x)\right] \leq 0 .
$$

(4) A mapping $T: C \rightarrow C$ is said to be totally quasi- $\phi$-asymptotically nonexpansive [38], if $F(T) \neq \emptyset$ and there exist nonnegative real sequences $\left\{\nu_{n}\right\},\left\{\mu_{n}\right\}$ satisfying $\nu_{n}, \mu_{n} \rightarrow 0($ as $n \rightarrow+\infty)$ and a strictly increasing continuous function $\zeta: R^{+} \rightarrow R^{+}$with $\zeta(0)=0$ such that

$$
\phi\left(p, T^{n} x\right) \leq \phi(p, x)+\nu_{n} \cdot \zeta[\phi(p, x)]+\mu_{n} \forall n \geq 1, x \in C, p \in F(T) .
$$


(5) A mapping $T: C \rightarrow C$ is said to be quasi- $\phi$-asymptotically nonexpansive [38, 47], if $F(T) \neq \emptyset$ and there exists a sequence $\left\{k_{n}\right\} \subset[1,+\infty)$ satisfying $\lim _{n \rightarrow+\infty} k_{n}=1$ such that $\phi\left(p, T^{n} x\right) \leq k_{n} \phi(p, x)$ for all $x \in C, p \in F(T)$ and $n \geq 1$.

(6) A mapping $T: C \rightarrow C$ is said to be quasi- $\phi$-asymptotically nonexpansive in the intermediate sense with sequence $\left\{\nu_{n}\right\}$, if $F(T) \neq \emptyset$ and there exists a sequence $\left\{\nu_{n}\right\}$ in $[0,+\infty)$ satisfying $\lim _{n \rightarrow+\infty} \nu_{n}=0$ such that

$$
\limsup _{n \rightarrow+\infty} \sup _{x \in C, p \in F(T)}\left[\phi\left(p, T^{n} x\right)-\left(1+\nu_{n}\right) \phi(p, x)\right] \leq 0 .
$$

Obviously, Bregman (totally $D$-asymptotically, $D$-asymptotically, respectively) nonexpansive mapping contains Bregman quasi- $D$-nonexpansive mapping, and (totally $\phi$-asymptotically, $\phi$-asymptotically, respectively) nonexpansive mapping as its special case. Indeed, if $E$ is a smooth Banach space and $g(x)=\|x\|^{2}$ for all $x \in E$, then we have that $D(x, y)=\phi(x, y)$ for all $x, y \in E$ and (totally $\phi$-asymptotically, $\phi$ asymptotically, respectively) nonexpansive mapping is reduced to the Bregman (totally $D$-asymptotically, $D$-asymptotically, respectively) nonexpansive mapping, but the converse is not true in general, in fact, let $g(x)=\|x\|^{p}$ for all $x \in E$ and $p \in(2,+\infty)$, then $D(x, y) \neq \phi(x, y)$ in general for some $x, y \in E$. Thus, a Bregman (totally $D$-asymptotically, $D$-asymptotically, respectively) nonexpansive mapping is not always a (totally $\phi$-asymptotically, $\phi$-asymptotically, respectively) nonexpansive mapping.

Let $C$ be a nonempty closed convex subset of $E$ and $T$ be a mapping from $C$ to itself. A point $p \in C$ is said to be an asymptotic fixed point of $T[6]$ if $C$ contains a sequence $\left\{x_{n}\right\}$ which converges weakly to $p$ such that $\lim _{n \rightarrow \infty}\left\|x_{n}-T x_{n}\right\|=0$. A point $p \in C$ is said to be a strong asymptotic fixed point of $T$ [28, 31] if $C$ has a sequence $\left\{x_{n}\right\}$ which converges strongly to $p$ such that $\lim _{n \rightarrow \infty}\left\|x_{n}-T x_{n}\right\|=0$. We denote the sets of asymptotic fixed points and strong asymptotic fixed points of $T$ by $\widehat{F}(T)$ and $\widetilde{F}(T)$, respectively.

\section{Definition 2.7.}

(1) A mapping $T$ from $C$ into itself is said to be Bregman relatively nonexpansive [2, 25], if $\widehat{F}(T)=$ $F(T) \neq \emptyset$ and $D(p, T x) \leq D(p, x)$ for all $x \in C$ and $p \in F(T) ;$

(2) $T$ is said to be Bregman weak relatively nonexpansive [1, 22, 24], if $\widetilde{F}(T)=F(T) \neq \emptyset$ and $D(p, T x) \leq$ $D(p, x)$ for all $x \in C$ and $p \in F(T)$;

(3) $T$ is said to be Bregman quasi- $D$-nonexpansive [29], if $F(T) \neq \emptyset$ and $D(p, T x) \leq D(p, x)$ for all $x \in C$ and $p \in F(T)$;

(4) $T$ is said to be Bregman firmly nonexpansive [21, 31, if

$$
\langle\nabla g(T x)-\nabla g(T y), T x-T y\rangle \leq\langle\nabla g(x)-\nabla g(y), T x-T y\rangle \forall x, y \in C,
$$

or, equivalently,

$$
D(T x, T y)+D(T y, T x)+D(T x, x)+D(T y, y) \leq D(T x, y)+D(T y, x) \forall x, y \in C
$$

(5) $T$ is said to be Bregman strongly nonexpansive [28, 45, 46], if $\widehat{F}(T) \neq \emptyset$ and $D(p, T x) \leq D(p, x)$ for all $x \in C$ and $p \in \widehat{F}(T)$ and if whenever $\left\{x_{n}\right\} \subset E$ is bounded, $p \in \widehat{F}(T)$ and $\lim _{n \rightarrow+\infty}\left[D\left(p, x_{n}\right)-\right.$ $\left.D\left(p, T x_{n}\right)\right]=0$, it follows that $\lim _{n \rightarrow+\infty} D\left(T x_{n}, x_{n}\right)=0$;

(6) $T$ is said to be relatively quasi-nonexpansive [33, 36], if $\widehat{F}(T)=F(T) \neq \emptyset$ and $\phi(p, T x) \leq \phi(p, x)$ for all $x \in C$ and $p \in F(T)$;

(7) $T$ is said to be weak relatively nonexpansive [33, 45], if $\widetilde{F}(T)=F(T) \neq \emptyset$ and $\phi(p, T x) \leq \phi(p, x)$ for all $x \in C$ and $p \in F(T)$; 
(8) $T$ is said to be quasi- $\phi$-nonexpansive [33, 47], if $F(T) \neq \emptyset$ and $\phi(p, T x) \leq \phi(p, x)$ for all $x \in C$ and $p \in F(T)$.

Remark 2.8 .

(1) If $\zeta(t)=t, t \geq 0$, then 2.1 is reduced to

$$
D\left(p, T^{n} x\right) \leq\left(1+\nu_{n}\right) \cdot D(p, x)+\mu_{n} \forall n \geq 1, x \in C, p \in F(T) .
$$

In addition, if $\mu_{n} \equiv 0$ for all $n \geq 1$, then Bregman totally quai- $D$-asymptotically nonexpansive mappings coincide with Bregman quai- $D$-asymptotically nonexpansive mappings. If $\mu_{n} \equiv 0$ and $\nu_{n} \equiv 0$ for all $n \geq 1$, we obtain from (2.4) the class of mappings that includes the class of Bregman quai-nonexpansive mappings. If $\nu_{n} \equiv 0$ and $\mu_{n}=\sigma_{n}=\max \left\{0, \sup _{x \in E, p \in F(T)}\left(D\left(p, T^{n} x\right)-D(p, x)\right)\right\}$ for all $n \geq 1$, then (2.4) is reduced to (2.3), which has been studied as Bregman quai- $D$-asymptotically nonexpansive mappings in the intermediate sense.

(2) From the definitions, it is obvious that if $\widehat{F}(T)=F(T) \neq \emptyset$, then a Bregman strongly nonexpansive mapping is a Bregman relatively nonexpansive mapping; A Bregman relatively nonexpansive mapping is a Bregman quasi- $D$-nonexpansive mapping. A Bregman quasi- $D$-nonexpansive mapping is a Bregman quasi- $D$-asymptotically nonexpansive mapping with $k_{n} \equiv 1$, but the converse is not true.

If one takes $\zeta(t)=t, t \geq 0, \nu_{n}=k_{n}-1, \mu_{n}=0, \lim _{n \rightarrow+\infty} k_{n}=1$, then (2.1) can be rewritten as (2.2). This implies that each Bregman quasi- $D$-asymptotically nonexpansive mapping must be a Bregman total quasi- $D$-asymptotically nonexpansive mapping, but the converse is not true. In [9], S. S. Chang et al. gave an example of Bregman total quasi- $D$-asymptotically nonexpansive mapping. A Bregman relatively nonexpansive mapping is a Bregman weak relatively nonexpansive mapping, but the converse is not true in general. Indeed, for any mapping $T: C \rightarrow C$, we have $F(T) \subset \widetilde{F}(T) \subset \widehat{F}(T)$. If $T$ is Bregman relatively nonexpansive, then $F(T)=\tilde{F}(T)=\widehat{F}(T)$. In [22], Naraghirad and Yao have given two examples of a Bregman weak relatively nonexpansive mapping which is not a Bregman relatively nonexpansive mapping, and a Bregman quasi-nonexpansive mapping which is neither a Bregman relatively nonexpansive mapping nor a Bregman weak relatively nonexpansive mapping.

(3) The class of quasi- $\phi$-(asymptotically) nonexpansive mappings is more general than that of relatively nonexpansive mappings which requires the restriction $\widehat{F}(T)=F(T)$. A quasi- $\phi$-nonexpansive mapping with a nonempty fixed point set $F(T)$ is a quasi- $\phi$-asymptotically nonexpansive mapping, but the converse may not be true. In Hilbert spaces, quasi- $\phi$-(asymptotically) nonexpansive mappings is reduced to quasi-(asymptotically) nonexpansive mappings.

The theory of fixed points with respect to Bregman distances has been studied in the last ten years and much intensively in the last six years. In [4], Bauschke and Combettes introduced an iterative method to construct the Bregman projection of a point onto a countable intersection of closed and convex sets in reflexive Banach spaces, they proved strong convergence theorem of the sequence produced by their method. For more details, see [[2], Theorem 4.6]. For some recent articles on the existence of fixed points for Bregman nonexpansive type mappings, we refer the readers to [1, 2, 4, 5, 17, 9, 10, 17, 21, 25, 29, 32, 35, 45, 46].

We need the following eight lemmas for our main results.

Lemma 2.9 (46]). Let $E$ be a Banach space and $g: E \rightarrow R$ a Gâteaux differentiable function which is locally uniformly convex on $E$. Let $\left\{y_{n}\right\}$ and $\left\{z_{n}\right\}$ be sequences in $E$ such that either $\left\{y_{n}\right\}$ or $\left\{z_{n}\right\}$ is bounded. Then the following assertions are equivalent: (1) $\lim _{n \rightarrow+\infty} D\left(y_{n}, z_{n}\right)=0 ;(2) \lim _{n \rightarrow+\infty}\left\|y_{n}-z_{n}\right\|=0$.

Lemma 2.10 ([22, 28]). Let $C$ be a nonempty closed convex subset of a reflexive Banach space $E$, Let $g: E \rightarrow R$ be a Gâteaux differentiable and totally convex function, and let $x \in E$. Then

(1) $z=\operatorname{Proj}_{C}^{g}(x)$ if and only if $\langle y-z, \nabla g(x)-\nabla g(z)\rangle \leq 0$, for all $y \in C$; 
(2) $D\left(y, \operatorname{Proj}_{C}^{g}(x)\right)+D\left(\operatorname{Proj}_{C}^{g}(x), x\right) \leq D(y, x)$, for all $x \in E, y \in C$;

(3) when the sequence $\left\{D\left(x_{n}, x\right)\right\}_{n \in N}$ is bounded, we have that the sequence $\left\{x_{n}\right\}_{n \in N}$ is bounded too.

Lemma 2.11 ([23]). Let $C$ be a nonempty closed convex subset of Banach space $E$ and $g: E \rightarrow(-\infty,+\infty]$ be a Gâteaux differentiable function which is locally uniformly convex on $E$. Let $T: C \rightarrow C$ be a closed and Bregman totally quasi-D-asymptotically nonexpansive mapping with nonnegative real sequences $\left\{\nu_{n}\right\},\left\{\mu_{n}\right\}$ and a strictly increasing and continuous function $\zeta: R^{+} \rightarrow R^{+}$satisfying $\zeta(0)=0$. If $\nu_{n}, \mu_{n} \rightarrow 0$ (as $n \rightarrow$ $+\infty)$, then $F(T)$ is a closed convex subset of $C$.

Lemma 2.12 ([22]). Let $E$ be a Banach space, $r>0$ be a positive number and $g: E \rightarrow R$ be a continuous and convex function which is uniformly convex on bounded subsets of $E$. Then

$$
g\left(\sum_{n=1}^{+\infty} \lambda_{n} x_{n}\right) \leq \sum_{n=1}^{+\infty} \lambda_{n} g\left(x_{n}\right)-\lambda_{i} \lambda_{j} \rho_{r}\left(\left\|x_{i}-x_{j}\right\|\right)
$$

for any given infinite subset $\left\{x_{n}\right\} \subset B_{r}(0)=\{x \in E:\|x\| \leq r\}$ and for any given sequence $\left\{\lambda_{n}\right\}$ of positive numbers with $\sum_{n=1}^{+\infty} \lambda_{n}=1$, for any $i, j \in N$ with $i<j$, where $\rho_{r}$ is the gauge of uniformly convexity of $g$.

For solving the equilibrium problem, let us assume that bifunction $f: C \times C \rightarrow R$ satisfies the following conditions:

(C1) $f(x, x)=0$, for all $x \in C$;

(C2) $f$ is monotone, i.e., $f(x, y)+f(y, x) \leq 0$, for all $x, y \in C$;

(C3) for each $y \in C$, the function $x \mapsto f(x, y)$ is upper semicontinuous;

(C4) for all $x \in C, y \mapsto f(x, y)$ is a convex and lower semicontinuous.

Lemma $2.13([1])$. Let $E$ be a reflexive Banach space and $g: E \rightarrow R$ a convex, continuous and strongly coercive function which is bounded on bounded subsets and uniformly convex on bounded subset of E. Let $C$ be a nonempty, closed and convex subset of $E$ and $f: C \times C \rightarrow R$ a bifunction satisfying conditions $(\mathrm{C} 1)-(\mathrm{C} 4)$ and $\operatorname{EP}(G) \neq \emptyset, \varphi: C \rightarrow R$ be a lower semicontinuous and convex functional, $A: C \rightarrow E^{*}$ be a continuous and monotone mapping. For $r>0$ and $x \in E$, define a mapping $T_{r}^{G}: E \rightarrow C$ as follows:

$$
T_{r}^{G} x=\left\{z \in C: G(z, y)+\frac{1}{r}\langle y-z, \nabla g(z)-\nabla g(x)\rangle \geq 0, \forall y \in C\right\},
$$

where $G(x, y)=f(x, y)+\varphi(y)-\varphi(x)+\langle A x, y-x\rangle$ for all $x, y \in E$. Then, the following statements hold:

(1) $\operatorname{dom}\left(T_{r}^{G}\right)=E$;

(2) $T_{r}^{G}$ is a Bregman firmly nonexpansive mapping, i.e., for all $x, y \in E$,

$$
\left\langle T_{r}^{G} x-T_{r}^{G} y, \nabla g\left(T_{r}^{G} x\right)-\nabla g\left(T_{r}^{G} y\right)\right\rangle \leq\left\langle T_{r}^{G} x-T_{r}^{G} y, \nabla g(x)-\nabla g(y)\right\rangle ;
$$

(3) $T_{r}^{G}$ is single-valued;

(4) $F\left(T_{r}^{G}\right)=G M E P(f, \varphi)$;

(5) $D\left(q, T_{r}^{G} x\right)+D\left(T_{r}^{G} x, x\right) \leq D(q, x) \forall q \in F\left(T_{r}^{G}\right)$;

(6) GMEP(f, $\varphi)$ is closed and convex subset of $C$.

Lemma 2.14 ([7, 25]). Let $E$ be a reflexive Banach space, $g: E \rightarrow R$ a strongly coercive Bregman function and the function $V$ defined by $V\left(x, x^{*}\right)=g(x)-\left\langle x, x^{*}\right\rangle+g^{*}\left(x^{*}\right)$ for all $x \in E, x^{*} \in E^{*}$. Then the following assertions hold: 
(1) $D\left(x, \nabla g^{*}\left(x^{*}\right)\right)=V\left(x, x^{*}\right)$ for all $x \in E, x^{*} \in E^{*}$;

(2) $V\left(x, x^{*}\right)+\left\langle\nabla g^{*}\left(x^{*}\right)-x, y^{*}\right\rangle \leq V\left(x, x^{*}+y^{*}\right)$ for all $x \in E$ and $x^{*}, y^{*} \in E^{*}$.

Lemma 2.15 ([44]). Let $E$ be a Banach space, let $g: E \rightarrow(-\infty,+\infty]$ be a proper, lower semicontinuous and convex function. Then the following statements are equivalent:

(1) There exists a constant $c_{1}>0$ such that $g$ is $\rho_{r}$-convex with $\rho_{r}(t):=\frac{c_{1}}{2} t^{2}$ for all $t \geq 0$.

(2) There exists a constant $c>0$ such that for all $x, y \in E$ and $x^{*} \in \partial g(x), y^{*} \in \partial g(y)$, we have $\left\|x^{*}-y^{*}\right\| \geq c\|x-y\|$, where $\frac{1}{c}$ is the 2 -uniformly convexity constant.

Lemma 2.16 ([44]). Let $E$ be a reflexive Banach space and let $g: E \rightarrow R$ be a convex, continuous and strongly coercive function. Then the following assertions are equivalent:

(1) $g$ is bounded on bounded subsets and uniformly smooth on bounded subsets of E;

(2) $g^{*}$ is Fréchet differentiable and $\nabla g^{*}$ is uniformly norm-to-norm continuous on bounded subsets of $E^{*}$;

(3) dom $g^{*}=E^{*}, g^{*}$ is strongly coercive and uniformly convex on bounded subsets of $E^{*}$.

\section{Main results}

Theorem 3.1. Let $E$ be a 2-uniformly convex Banach space and $g: E \rightarrow R$ be a strongly coercive Bregman function which is bounded on bounded subsets and uniformly smooth and 2-uniformly convex on bounded subsets of $E$. Let $C$ be a nonempty, closed and convex subset of $E$. Suppose $B: C \rightarrow E^{*}$ is an $\alpha$ inverse-strongly monotone operator satisfying $(B 1)-(B 2)$. For each $k=1,2, \cdots, m$, let $A_{k}: C \rightarrow E^{*}$ be a continuous and monotone mapping, $\varphi_{k}: C \rightarrow R$ be a lower semicontinuous and convex functional, let $f_{k}: C \times C \rightarrow R$ be a bifunction satisfying $(C 1)-(C 4)$ and $T_{i}: C \rightarrow C$ for all $i \in N$ be an infinite family of closed and uniformly Bregman totally quasi-D-asymptotically nonexpansive mappings with nonnegative real sequences $\left\{\nu_{n}^{(i)}\right\},\left\{\mu_{n}^{(i)}\right\}$ and a strictly increasing and continuous function $\zeta: R^{+} \rightarrow R^{+}$with $\zeta(0)=0$. $\lim _{n \rightarrow+\infty} \sup _{i \geq 0}\left\{\nu_{n}^{(i)}\right\}=0$ and $\lim _{n \rightarrow+\infty} \sup _{i \geq 0}\left\{\mu_{n}^{(i)}\right\}=0, T_{0}=I$ and $I$ is the identity mapping on $C$. Assume that $F:=\left[\bigcap_{i=0}^{+\infty} F\left(T_{i}\right)\right] \cap\left[\bigcap_{k=1}^{m} \operatorname{GMEP}\left(f_{k}, \varphi_{k}\right)\right] \cap V I(C, B) \neq \emptyset$ and $T_{i}$ is uniformly asymptotic regular on $C$ for all $i \geq 0$, i.e., $\lim _{n \rightarrow+\infty} \sup _{x \in K}\left\|T_{i}^{n+1} x-T_{i}^{n} x\right\|=0$ holds for any bounded subset $K$ of $C$. For each $k=1,2, \cdots, m,\left\{r_{k, n}\right\}_{n=1}^{+\infty} \subset(0,+\infty)$ satisfying $\liminf _{n \rightarrow+\infty} r_{k, n}>0$ for all $z, y \in C$,

$$
\begin{aligned}
& G_{k}(z, y)=f_{k}(z, y)+\varphi_{k}(y)-\varphi_{k}(z)+\left\langle A_{k} z, y-z\right\rangle, \\
& T_{r_{k, n}}^{G_{k}}(x)=\left\{z \in C: G_{k}(z, y)+\frac{1}{r_{k, n}}\langle y-z, \nabla g(z)-\nabla g(x)\rangle \geq 0, \forall y \in C\right\} .
\end{aligned}
$$

Let $\left\{x_{n}\right\}$ be a sequence generated by

$$
\left\{\begin{array}{l}
x_{0} \in C \text { chosen arbitrarily, } \\
C_{0}=C, \\
y_{n}=\nabla g^{*}\left\{\alpha_{n} \nabla g\left(\operatorname{Proj}_{C}^{g}\left[\nabla g^{*}\left(\nabla g\left(x_{n}\right)-\lambda_{n} B x_{n}\right)\right]\right)+\left(1-\alpha_{n}\right) \nabla g\left(z_{n}\right)\right\}, \\
z_{n}=\nabla g^{*}\left[\sum_{i=0}^{+\infty} \beta_{n}^{(i)} \nabla g\left(T_{i}^{n} x_{n}\right)\right], \\
u_{n}=T_{r_{m, n}}^{G_{m}} T_{r_{m-1, n}}^{G_{m-1}} \cdots T_{r_{2, n}}^{G_{2}} T_{r_{1, n}}^{G_{1}} y_{n}, \\
C_{n+1}=\left\{z \in C_{n}: D\left(z, u_{n}\right) \leq \alpha_{n} D\left(z, x_{n}\right)+\left(1-\alpha_{n}\right) D\left(z, z_{n}\right) \leq D\left(z, x_{n}\right)+\omega_{n}\right\}, \\
x_{n+1}=\operatorname{Proj}_{C_{n+1}}^{g}\left(x_{0}\right),
\end{array}\right.
$$


where $\omega_{n}=\sup _{i \geq 0}\left\{\nu_{n}^{(i)}\right\} \cdot \sup _{p \in F}\left\{\zeta\left[D\left(p, x_{n}\right)\right]\right\}+\sup _{i \geq 0}\left\{\mu_{n}^{(i)}\right\}<+\infty$ for each $n \geq 0,\left\{\lambda_{n}\right\} \subset[a, b]$ for some $a, b$ with $0<a<b<c \alpha$, where $\frac{1}{c}$ is 2-uniformly convexity constant of E satisfying Lemma 2.15 (2), $\left\{\alpha_{n}\right\}$, $\left\{\beta_{n}^{(i)}\right\}(i \in N)$ are real sequences in $[0,1]$ satisfy the conditions:

$$
\forall n \geq 0, \sum_{i=0}^{\infty} \beta_{n}^{(i)}=1, \liminf _{n \rightarrow \infty}\left(1-\alpha_{n}\right) \beta_{n}^{(0)} \beta_{n}^{(i)}>0 \forall i \in N .
$$

Then the sequence $\left\{x_{n}\right\}$ converges strongly to $\operatorname{Proj}_{F}^{g} x_{0}$.

Proof. We define a bifunction $G_{k}: C \times C \rightarrow R$ by

$$
G_{k}(x, y)=f_{k}(x, y)+\varphi_{k}(y)-\varphi_{k}(x)+\left\langle A_{k} x, y-x\right\rangle \forall x, y \in C .
$$

Then, we may prove from Lemma 2.13 that the bifunction $G_{k}$ satisfies conditions (C1)-(C4) for each $k=1,2, \cdots, m$. Therefore, the generalized mixed equilibrium problem 1.1) is equivalent to the following equilibrium problem: find $x \in C$ such that $G_{k}(x, y) \geq 0$, for all $y \in C$. Hence, $\operatorname{GMEP}\left(f_{k}, \varphi_{k}\right)=E P\left(G_{k}\right)$. By taking $\theta_{n}^{k}=T_{r_{k, n}}^{G_{k}} T_{r_{k-1, n}}^{G_{k-1}} \cdots T_{r_{2}, n}^{G_{2}} T_{r_{1, n}}^{G_{1}}, k=1,2, \cdots, m$ and $\theta_{n}^{0}=I$ for all $n \geq 0$, we obtain $u_{n}=\theta_{n}^{m} y_{n}$. Let $t_{n}=\nabla g^{*}\left[\nabla g\left(x_{n}\right)-\lambda_{n} B x_{n}\right]$. In view of Lemma 2.12, Lemma 2.13, and the closeness and convexity of $V I(C, B)$, we find that $F$ is closed and convex subset of $C$, so that $\operatorname{Proj}_{F}^{g} x_{0}$ is well-defined for any $x_{0} \in C$. We divide the proof of Theorem 3.1 into six steps:

Step 1. We first show that $C_{n}$ is both closed and convex for each $n \geq 1$.

In fact, for $z \in C_{m}$, we see that

$$
D\left(z, u_{m}\right) \leq \alpha_{m} D\left(z, x_{m}\right)+\left(1-\alpha_{m}\right) D\left(z, z_{m}\right) \leq D\left(z, x_{m}\right)+\omega_{m}
$$

is equivalent to

$$
\left\langle z-u_{m}, \alpha_{m} \nabla g\left(x_{m}\right)+\left(1-\alpha_{m}\right) \nabla g\left(z_{m}\right)-\nabla g\left(u_{m}\right)\right\rangle \leq \alpha_{m} D\left(u_{m}, x_{m}\right)+\left(1-\alpha_{m}\right) D\left(u_{m}, z_{m}\right)-g\left(u_{m}\right)
$$

and

$$
\left(1-\alpha_{m}\right)\left\langle z-x_{m}, \nabla g\left(x_{m}\right)-\nabla g\left(z_{m}\right)\right\rangle \leq-\left(1-\alpha_{m}\right) D\left(x_{m}, z_{m}\right)+\omega_{m}
$$

The last two inequalities are affine with respect to $z$, so $C_{n}$ is closed and convex.

Step 2. Assume that $F \subset C_{n}$ for all $n \geq 0$. Then the sequence $\left\{x_{n}\right\}$ is bounded. In fact, by the construction of $C_{n}$, we have that $x_{n}=\operatorname{Proj}_{C_{n}}^{g}\left(x_{0}\right)$, then it follows from Lemma 2.10 that

$$
D\left(x_{n}, x_{0}\right)=D\left(\operatorname{Proj}_{C_{n}}^{g}\left(x_{0}\right), x_{0}\right) \leq D\left(p, x_{0}\right)-D\left(p, x_{n}\right) \leq D\left(p, x_{0}\right)
$$

for each $p \in F \subset C_{n}$ for all $n \geq 0$. Hence, the sequence $\left\{D\left(x_{n}, x_{0}\right)\right\}$ is bounded. Thus, by Lemma 2.10 , $\left\{x_{n}\right\}$ is bounded and so are $\left\{T_{i} x_{n}\right\},\left\{y_{n}\right\},\left\{z_{n}\right\},\left\{u_{n}\right\}$.

Step 3. Next, we show that $F \subset C_{n}$ for all $n \geq 0$.

In fact, it is obvious that $F \subset C_{0}=C$. Assume now that $F \subset C_{n}$ for some $n \in N$. It follows from the definition of $D(\cdot, \cdot)$ and $T_{i}$, Lemma 2.12, and (3.1) that, for each $p \in F \subset C_{n}$, we have

$$
\begin{aligned}
D\left(p, z_{n}\right) & =D\left(p, \nabla g^{*}\left[\sum_{i=0}^{+\infty} \beta_{n}^{(i)} \nabla g\left(T_{i}^{n} x_{n}\right)\right]\right) \\
& \leq \sum_{i=0}^{+\infty} \beta_{n}^{(i)} D\left(p, T_{i}^{n} x_{n}\right) \\
& \leq \sum_{i=0}^{+\infty} \beta_{n}^{(i)}\left\{D\left(p, x_{n}\right)+\nu_{n}^{(i)} \zeta\left[D\left(p, x_{n}\right)\right]+\mu_{n}^{(i)}\right\} \\
& \leq \sum_{i=0}^{+\infty} \beta_{n}^{(i)}\left[D\left(p, x_{n}\right)+\omega_{n}\right] \\
& =D\left(p, x_{n}\right)+\omega_{n} .
\end{aligned}
$$


Observe that $p \in F$ implies $p \in C$, by Lemma 2.10, Lemma 2.14, and (3.1), for all $p \in C$, we have

$$
\begin{aligned}
D\left(p, \operatorname{Proj}_{C}^{g}\left(t_{n}\right)\right) & \leq D\left(p, t_{n}\right)-D\left(\operatorname{Proj}_{C}^{g}\left(t_{n}\right), t_{n}\right) \\
& \leq D\left(p, t_{n}\right) \\
& =V\left(p, \nabla g\left(x_{n}\right)-\lambda_{n} B x_{n}\right) \\
& \leq V\left(p,\left[\nabla g\left(x_{n}\right)-\lambda_{n} B x_{n}\right]+\lambda_{n} B x_{n}\right)-\left\langle\nabla g^{*}\left[\nabla g\left(x_{n}\right)-\lambda_{n} B x_{n}\right]-p, \lambda_{n} B x_{n}\right\rangle \\
& =V\left(p, \nabla g\left(x_{n}\right)\right)-\lambda_{n}\left\langle t_{n}-p, B x_{n}\right\rangle \\
& =D\left(p, x_{n}\right)-\lambda_{n}\left\langle x_{n}-p, B x_{n}\right\rangle+\left\langle t_{n}-x_{n},-\lambda_{n} B x_{n}\right\rangle .
\end{aligned}
$$

From $p \in V I(C, B)$ and the fact that $B$ is an $\alpha$-inverse-strongly monotone operator, we obtain

$$
-\lambda_{n}\left\langle x_{n}-p, B x_{n}\right\rangle=-\lambda_{n}\left\langle x_{n}-p, B x_{n}-B p\right\rangle-\lambda_{n}\left\langle x_{n}-p, B p\right\rangle \leq-\lambda_{n} \alpha\left\|B x_{n}-B p\right\|^{2} .
$$

By Lemma 2.15 and condition (B2), we also obtain

$$
\begin{aligned}
\left\langle t_{n}-x_{n},-\lambda_{n} B x_{n}\right\rangle & \leq\left\|t_{n}-x_{n}\right\| \cdot \lambda_{n}\left\|B x_{n}\right\| \\
& \leq \frac{1}{c}\left\|\nabla g\left(t_{n}\right)-\nabla g\left(x_{n}\right)\right\| \cdot \lambda_{n}\left\|B x_{n}\right\| \\
& =\frac{1}{c} \lambda_{n}^{2} \cdot\left\|B x_{n}\right\|^{2} \\
& \leq \frac{1}{c} \lambda_{n}^{2}\left\|B x_{n}-B p\right\|^{2} .
\end{aligned}
$$

Combining (3.3)-(3.5), $\lambda_{n} \in[a, b]$ and $0<b<c \alpha$, we obtain

$$
D\left(p, \operatorname{Proj}_{C}^{g}\left(t_{n}\right)\right) \leq D\left(p, t_{n}\right) \leq D\left(p, x_{n}\right)+\lambda_{n}\left(\frac{b}{c}-\alpha\right) \cdot\left\|B x_{n}-B p\right\|^{2} \leq D\left(p, x_{n}\right) .
$$

Thus, by (3.1)-(3.3), Lemma 2.12, Lemma 2.13, and the fact that $T_{r_{k, n}}^{G_{k}}(k=1,2, \cdots, m)$ is a Bregman quasi- $D$-nonexpansive mapping, for each $p \in F$, we obtain

$$
\begin{aligned}
D\left(p, u_{n}\right) & =D\left(p, \theta_{n}^{m} y_{n}\right) \\
& \leq D\left(p, y_{n}\right) \\
& =D\left(p, \nabla g^{*}\left[\alpha_{n} \nabla g\left(\operatorname{Proj}_{C}^{g}\left(t_{n}\right)\right)+\left(1-\alpha_{n}\right) \nabla g\left(z_{n}\right)\right]\right) \\
& \leq \alpha_{n} D\left(p, \operatorname{Proj}_{C}^{g}\left(t_{n}\right)\right)+\left(1-\alpha_{n}\right) D\left(p, z_{n}\right) \\
& \leq \alpha_{n} D\left(p, x_{n}\right)+\left(1-\alpha_{n}\right) D\left(p, z_{n}\right) \\
& \leq \alpha_{n} D\left(p, x_{n}\right)+\left(1-\alpha_{n}\right)\left[D\left(p, x_{n}\right)+\omega_{n}\right] \\
& \leq D\left(p, x_{n}\right)+\omega_{n} .
\end{aligned}
$$

This proves that $p \in C_{n+1}$. Consequently, we see that $F \subset C_{n}$ for any $n \in N$.

Step 4. Now, we show that $\left\{x_{n}\right\}$ is Cauchy sequence.

In fact, combining $x_{n+1}=\operatorname{Proj}_{C_{n+1}}^{g}\left(x_{0}\right) \in C_{n+1} \subset C_{n}$ and Lemma 2.10 , we obtain

$$
0 \leq D\left(x_{n}, x_{n+1}\right) \leq D\left(x_{n}, x_{0}\right)-D\left(x_{n+1}, x_{0}\right)
$$

for all $n \geq 0$. Thus, the sequence $\left\{D\left(x_{n}, x_{0}\right)\right\}$ is nondecreasing. It follows from the boundedness of $\left\{D\left(x_{n}, x_{0}\right)\right\}$ that the limit of $\left\{D\left(x_{n}, x_{0}\right)\right\}$ exists.

For any positive integer $m$, it then follows from Lemma 2.10 and existence of the limit of $\left\{D\left(x_{n}, x_{0}\right)\right\}$ that

$$
\begin{aligned}
D\left(x_{n+m}, x_{n}\right) & =D\left(x_{n+m}, \operatorname{Proj}_{C_{n}}^{g}\left(x_{0}\right)\right) \\
& \leq D\left(x_{n+m}, x_{0}\right)-D\left(\operatorname{Proj}_{C_{n}}^{g}\left(x_{0}\right), x_{0}\right) \\
& =D\left(x_{n+m}, x_{0}\right)-D\left(x_{n}, x_{0}\right) .
\end{aligned}
$$


It follows from 3.8 that $D\left(x_{n+m}, x_{n}\right) \rightarrow 0$ as $n \rightarrow \infty$. We have from the boundedness of $\left\{D\left(x_{n}, x_{0}\right)\right\}$ that $\left\{x_{n}\right\}$ is bounded and combining Lemma 2.9 , we obtain

$$
x_{n+m}-x_{n} \rightarrow 0, n \rightarrow \infty .
$$

Hence, the sequence $\left\{x_{n}\right\}$ is Cauchy in $C$. Since $E$ is a Banach space and $C$ is closed, then there exists $p \in C$ such that $x_{n} \rightarrow p$ as $n \rightarrow \infty$. Now, since $D\left(x_{n+m}, x_{n}\right) \rightarrow 0$ as $n \rightarrow \infty$ for any positive integer $m$, we have in particular that $\lim _{n \rightarrow \infty} D\left(x_{n+1}, x_{n}\right)=0$ and this further implies from Lemma 2.9 that $\lim _{n \rightarrow \infty}\left\|x_{n+1}-x_{n}\right\|=0$. Since $x_{n+1}=\operatorname{Proj}_{C_{n+1}}^{g}\left(x_{0}\right) \in C_{n+1} \subset C_{n}$ and $\lim _{n \rightarrow \infty} \omega_{n}=0$, we have

$$
D\left(x_{n+1}, u_{n}\right) \leq D\left(x_{n+1}, x_{n}\right)+\omega_{n} \rightarrow 0, n \rightarrow \infty .
$$

From Lemma 2.9, we obtain that $\lim _{n \rightarrow \infty}\left\|x_{n+1}-u_{n}\right\|=0$. Therefore

$$
\left\|x_{n}-u_{n}\right\| \leq\left\|x_{n}-x_{n+1}\right\|+\left\|x_{n+1}-u_{n}\right\| \rightarrow 0 .
$$

It follows from $\lim _{n \rightarrow+\infty}\left\|x_{n}-p\right\|=0$ and (3.9) that

$$
u_{n} \rightarrow p, n \rightarrow \infty \text {. }
$$

Step 5. Now we prove that $p \in\left[\bigcap_{i=0}^{+\infty} F\left(T_{i}\right)\right] \cap\left[\bigcap_{k=1}^{m} G M E P\left(f_{k}, \varphi_{k}\right)\right] \cap V I(C, B)$.

(a) First we prove that $p \in \bigcap_{i=0}^{+\infty} F\left(T_{i}\right)$.

Since $g$ is bounded on bounded subsets and uniformly smooth on bounded subsets of $E$, we have from Lemma 2.16 that $\nabla g(\cdot)$ is uniformly norm-to-norm continuous on any bounded sets and combining $(3.9)$, we obtain

$$
\lim _{n \rightarrow \infty}\left\|\nabla g\left(x_{n}\right)-\nabla g\left(u_{n}\right)\right\|=0 .
$$

It follows from the boundedness of the sequences $\left\{x_{n}\right\}$ and $\left\{\zeta_{n}\right\}, D\left(p, T_{i}^{n} x_{n}\right) \leq D\left(p, x_{n}\right)+\zeta_{n}$ for each $p \in F, i \in N$ that the sequences $\left\{\nabla g\left(T_{i}^{n} x_{n}\right)\right\}$ are bounded. In view of Lemma 2.16, we know that $\operatorname{dom} g^{*}=E^{*}$ and $g^{*}$ is strongly coercive and uniformly convex on bounded subsets of $E^{*}$. Let $r=$ $\sup \left\{\left\|\nabla g\left(x_{n}\right)\right\|,\left\|\nabla g\left(T_{i}^{n} x_{n}\right)\right\|: i \in N, n \in N\right\}$ and $\rho_{r}^{*}: E^{*} \rightarrow R$ be the gauge of uniformly convexity of the conjugate function $g^{*}$. For each $p \in F$, we have from Lemma 2.12, Lemma 2.13 and (3.6) that

$$
\begin{aligned}
D\left(p, u_{n}\right) & =D\left(p, \theta_{n}^{m} y_{n}\right) \\
& \leq D\left(p, y_{n}\right) \\
& =D\left(p, \nabla g^{*}\left[\alpha_{n} \nabla g\left(\operatorname{Proj}_{C}^{g}\left(t_{n}\right)\right)+\left(1-\alpha_{n}\right) \nabla g\left(z_{n}\right)\right]\right) \\
& \leq \alpha_{n} D\left(p, \operatorname{Proj}_{C}^{g}\left(t_{n}\right)\right)+\left(1-\alpha_{n}\right) D\left(p, z_{n}\right) \\
& \leq \alpha_{n} D\left(p, \operatorname{Proj}_{C}^{g}\left(t_{n}\right)\right)+\left(1-\alpha_{n}\right) \cdot\left(\sum_{i=0}^{+\infty} \beta_{n}^{(i)} D\left(p, T_{i}^{n} x_{n}\right)-\beta_{n}^{(0)} \beta_{n}^{(i)} \rho_{r}^{*}\left(\left\|\nabla g\left(T_{0}^{n} x_{n}\right)-\nabla g\left(T_{i}^{n} x_{n}\right)\right\|\right)\right) \\
& \leq \alpha_{n} D\left(p, x_{n}\right)+\left(1-\alpha_{n}\right) \cdot\left(\sum_{i=0}^{+\infty} \beta_{n}^{(i)}\left[D\left(p, x_{n}\right)+\omega_{n}\right]-\beta_{n}^{(0)} \beta_{n}^{(i)} \rho_{r}^{*}\left(\left\|\nabla g\left(T_{0}^{n} x_{n}\right)-\nabla g\left(T_{i}^{n} x_{n}\right)\right\|\right)\right) \\
& \leq \alpha_{n} D\left(p, x_{n}\right)+\left(1-\alpha_{n}\right) D\left(p, x_{n}\right)+\omega_{n}-\left(1-\alpha_{n}\right) \beta_{n}^{(0)} \beta_{n}^{(i)} \rho_{r}^{*}\left(\left\|\nabla g\left(T_{0}^{n} x_{n}\right)-\nabla g\left(T_{i}^{n} x_{n}\right)\right\|\right) \\
& =D\left(p, x_{n}\right)+\omega_{n}-\left(1-\alpha_{n}\right) \beta_{n}^{(0)} \beta_{n}^{(i)} \rho_{r}^{*}\left(\left\|\nabla g\left(T_{0}^{n} x_{n}\right)-\nabla g\left(T_{i}^{n} x_{n}\right)\right\|\right) .
\end{aligned}
$$

This implies that

$$
0 \leq\left(1-\alpha_{n}\right) \beta_{n}^{(0)} \beta_{n}^{(i)} \rho_{r}^{*}\left(\left\|\nabla g\left(T_{0}^{n} x_{n}\right)-\nabla g\left(T_{i}^{n} x_{n}\right)\right\|\right) \leq D\left(p, x_{n}\right)-D\left(p, u_{n}\right)+\omega_{n} .
$$

On the other hand, it follows from the three point identity (see Remark 2.8 (1)) that

$$
\begin{aligned}
\left|D\left(p, x_{n}\right)-D\left(p, u_{n}\right)\right| & =\left|-D\left(x_{n}, u_{n}\right)+\left\langle x_{n}-p, \nabla g\left(u_{n}\right)-\nabla g\left(x_{n}\right)\right\rangle\right| \\
& \leq D\left(x_{n}, u_{n}\right)+\left\|x_{n}-p\right\| \cdot\left\|\nabla g\left(u_{n}\right)-\nabla g\left(x_{n}\right)\right\| .
\end{aligned}
$$


In view of 3.9 and 3.11 , we obtain

$$
D\left(p, x_{n}\right)-D\left(p, u_{n}\right) \rightarrow 0, n \rightarrow \infty .
$$

Combining (3.12) and (3.13), $\lim _{n \rightarrow+\infty} \zeta_{n}=0, T_{0}=I$ and $\liminf _{n \rightarrow \infty}\left(1-\alpha_{n}\right) \beta_{n}^{(0)} \beta_{n}^{(i)}>0$, we have

$$
\rho_{r}^{*}\left(\left\|\nabla g\left(T_{0}^{n} x_{n}\right)-\nabla g\left(T_{i}^{n} x_{n}\right)\right\|\right) \rightarrow 0, n \rightarrow \infty .
$$

It follows from the property of $\rho_{r}^{*}$ that

$$
\lim _{n \rightarrow+\infty}\left\|\nabla g\left(x_{n}\right)-\nabla g\left(T_{i}^{n} x_{n}\right)\right\|=0 .
$$

Since $x_{n} \rightarrow p$ as $n \rightarrow \infty$ and $\nabla g(\cdot)$ is uniformly norm-to-norm continuous on any bounded sets, we obtain that

$$
\left\|\nabla g\left(x_{n}\right)-\nabla g(p)\right\| \rightarrow 0 \text { as } n \rightarrow \infty .
$$

Note that $\left\|\nabla g\left(T_{i}^{n} x_{n}\right)-\nabla g(p)\right\| \leq\left\|\nabla g\left(x_{n}\right)-\nabla g\left(T_{i}^{n} x_{n}\right)\right\|+\left\|\nabla g\left(x_{n}\right)-\nabla g(p)\right\|$. From (3.14) and (3.15), we see that

$$
\lim _{n \rightarrow+\infty}\left\|\nabla g\left(T_{i}^{n} x_{n}\right)-\nabla g(p)\right\|=0 .
$$

Observe that $\nabla g^{*}(\cdot)$ is also uniformly norm-to-norm continuous on any bounded sets. It follows from (3.16) that

$$
\lim _{n \rightarrow+\infty}\left\|T_{i}^{n} x_{n}-p\right\|=0 .
$$

Using $\left\|T_{i}^{n+1} x_{n}-p\right\| \leq\left\|T_{i}^{n+1} x_{n}-T_{i}^{n} x_{n}\right\|+\left\|T_{i}^{n} x_{n}-p\right\|$, the uniformly asymptotic regularity of $T_{i}$ and (3.17), we have $\lim _{n \rightarrow+\infty}\left\|T_{i}^{n+1} x_{n}-p\right\|=0$. That is, $T_{i}\left(T_{i}^{n} x_{n}\right) \rightarrow p$ as $n \rightarrow \infty$, it follows from the closeness of $T_{i}$ that $T_{i} p=p$ for all $i \in N$, i.e., $p \in \bigcap_{i=0}^{+\infty} F\left(T_{i}\right)$.

(b) Now we prove that $p \in \bigcap_{k=1}^{m} \operatorname{GMEP}\left(f_{k}, \varphi_{k}\right)=\bigcap_{k=1}^{m} E P\left(G_{k}\right)$.

In fact, in view of $u_{n}=\theta_{n}^{m} y_{n},(3.7)$ and Lemma 2.13, for each $q \in F\left(\theta_{n}^{k}\right)$, we have

$$
0 \leq D\left(u_{n}, y_{n}\right)=D\left(\theta_{n}^{m} y_{n}, y_{n}\right) \leq D\left(p, y_{n}\right)-D\left(p, \theta_{n}^{m} y_{n}\right) \leq D\left(p, x_{n}\right)-D\left(p, u_{n}\right)+\omega_{n} .
$$

It follows from (3.13) and $\lim _{n \rightarrow+\infty} \omega_{n}=0$ that $D\left(u_{n}, y_{n}\right) \rightarrow 0$ as $n \rightarrow \infty$. Using Lemma 2.9, we see that $\left\|u_{n}-y_{n}\right\| \rightarrow 0$ as $n \rightarrow \infty$. Furthermore, $\left\|x_{n}-y_{n}\right\| \leq\left\|x_{n}-u_{n}\right\|+\left\|u_{n}-y_{n}\right\| \rightarrow 0$ as $n \rightarrow \infty$. Since $x_{n} \rightarrow p$, as $n \rightarrow \infty$ and $\left\|x_{n}-y_{n}\right\| \rightarrow 0$, as $n \rightarrow \infty$, then $y_{n} \rightarrow p$, as $n \rightarrow \infty$. By the fact that $\theta_{n}^{k}(k=1,2, \cdots, m)$ is a Bregman quasi- $D$-nonexpansive mapping and using Lemma 2.13 and (3.7) again, we have that

$$
0 \leq D\left(\theta_{n}^{k} y_{n}, y_{n}\right) \leq D\left(p, y_{n}\right)-D\left(p, \theta_{n}^{k} y_{n}\right) \leq D\left(p, x_{n}\right)-D\left(p, \theta_{n}^{k} y_{n}\right)+\omega_{n} .
$$

Observe that

$$
\begin{aligned}
D\left(p, u_{n}\right) & =D\left(p, \theta_{n}^{m} y_{n}\right)=D\left(p, T_{r_{m, n}}^{G_{m}} T_{r_{m-1, n}}^{G_{m-1}} \cdots T_{r_{2, n}}^{G_{2}} T_{r_{1, n}}^{G_{1}} y_{n}\right) \\
& =D\left(p, T_{r_{m, n}}^{G_{m}} T_{r_{m-1, n}}^{G_{m-1}} \cdots \theta_{n}^{k} y_{n}\right) \leq D\left(p, \theta_{n}^{k} y_{n}\right) .
\end{aligned}
$$

Using (3.19) in (3.18), we obtain that $0 \leq D\left(\theta_{n}^{k} y_{n}, y_{n}\right) \leq D\left(p, x_{n}\right)-D\left(p, u_{n}\right)+\omega_{n} \rightarrow 0$ as $n \rightarrow \infty$. Then Lemma 2.9 implies that $\lim _{n \rightarrow \infty}\left\|\theta_{n}^{k} y_{n}-y_{n}\right\|=0, k=1,2, \cdots, m$. Now

$$
\left\|\theta_{n}^{k} y_{n}-p\right\| \leq\left\|\theta_{n}^{k} y_{n}-y_{n}\right\|+\left\|y_{n}-p\right\| \rightarrow 0, n \rightarrow \infty,
$$

$k=1,2, \cdots, m$. Similarly, $\lim _{n \rightarrow+\infty}\left\|\theta_{n}^{k-1} y_{n}-p\right\|=0, k=1,2, \cdots, m$. This further implies that

$$
\lim _{n \rightarrow+\infty}\left\|\theta_{n}^{k-1} y_{n}-\theta_{n}^{k} y_{n}\right\|=0
$$


Also, since $\nabla g(\cdot)$ is uniformly norm-to-norm continuous on any bounded sets and using (3.20), we obtain that $\lim _{n \rightarrow+\infty}\left\|\nabla g\left(\theta_{n}^{k} y_{n}\right)-\nabla g\left(\theta_{n}^{k-1} y_{n}\right)\right\|=0$. From $\left\{r_{k, n}\right\}_{n=1}^{+\infty} \subset(0,+\infty)$ satisfying $\liminf _{n \rightarrow+\infty} r_{k, n}>0$ for each $k=1,2, \cdots, m$, we see that

$$
\lim _{n \rightarrow \infty} \frac{\left\|\nabla g\left(\theta_{n}^{k} y_{n}\right)-\nabla g\left(\theta_{n}^{k-1} y_{n}\right)\right\|}{r_{k, n}}=0 .
$$

By Lemma 2.13, we have that for each $k=1,2, \cdots, m$,

$$
G_{k}\left(\theta_{n}^{k} y_{n}, y\right)+\frac{1}{r_{k, n}}\left\langle y-\theta_{n}^{k} y_{n}, \nabla g\left(\theta_{n}^{k} y_{n}\right)-\nabla g\left(\theta_{n}^{k-1} y_{n}\right)\right\rangle \geq 0, \forall y \in C
$$

Furthermore, replacing $n$ by $n_{j}$ in the last inequality and using condition (C2), we obtain

$$
\begin{aligned}
\left\|y-\theta_{n_{j}}^{k} y_{n_{j}}\right\| \cdot \frac{\left\|\nabla g\left(\theta_{n_{j}}^{k} y_{n_{j}}\right)-\nabla g\left(\theta_{n_{j}}^{k-1} y_{n_{j}}\right)\right\|}{r_{k, n_{j}}} & \geq \frac{1}{r_{k, n_{j}}}\left\langle y-\theta_{n_{j}}^{k} y_{n_{j}}, \nabla g\left(\theta_{n_{j}}^{k} y_{n_{j}}\right)-\nabla g\left(\theta_{n_{j}}^{k-1} y_{n_{j}}\right)\right\rangle \\
& \geq-G_{k}\left(\theta_{n_{j}}^{k} y_{n_{j}}, y\right) \geq G_{k}\left(y, \theta_{n_{j}}^{k} y_{n_{j}}\right) \forall y \in C .
\end{aligned}
$$

By taking the limit as $j \rightarrow+\infty$ in the above inequality, for each $k=1,2, \cdots, m$, we have from the condition (C4), (3.21) and $\theta_{n_{j}}^{k} y_{n_{j}} \rightarrow p$ as $j \rightarrow+\infty$ that $G_{k}(y, p) \leq 0$, for all $y \in C$.

For $0<t \leq 1$ and $y \in C$, define $y_{t}=t y+(1-t) p$. It follows from $y, p \in C$ and the convexity of $C$ that $y_{t} \in C$, which yields that $G_{k}\left(y_{t}, p\right) \leq 0$. It follows from the conditions $(\mathrm{C} 1)$ and $(\mathrm{C} 4)$ that

$$
0=G_{k}\left(y_{t}, y_{t}\right) \leq t G_{k}\left(y_{t}, y\right)+(1-t) G_{k}\left(y_{t}, p\right) \leq t G_{k}\left(y_{t}, y\right) .
$$

That is,

$$
G_{k}\left(y_{t}, y\right) \geq 0 .
$$

Let $t \rightarrow 0^{+}$, from the condition (C3), then we obtain that $G_{k}(p, y) \geq 0, \forall y \in C$. This implies that $p \in \operatorname{EP}\left(G_{k}\right), k=1,2, \cdots, m$, i.e., $p \in \bigcap_{k=1}^{m} \operatorname{EP}\left(G_{k}\right)=\bigcap_{k=1}^{m} G M E P\left(f_{k}, \varphi_{k}\right)$.

(c) Next we prove that $\lim _{n \rightarrow \infty}\left\|x_{n}-\operatorname{Proj}_{C}^{g}\left(t_{n}\right)\right\|=0$.

In fact, it follows from Lemma 2.10, Lemma 2.14, 3.5), (3.9), 3.10), and $\frac{1}{\alpha}$-Lipschitzian of $B$ that

$$
\begin{aligned}
D\left(x_{n}, \operatorname{Proj}_{C}^{g}\left(t_{n}\right)\right) & \leq D\left(x_{n}, t_{n}\right)-D\left(\operatorname{Proj}_{C}^{g}\left(t_{n}\right), t_{n}\right) \\
& \leq D\left(x_{n}, t_{n}\right) \\
& =V\left(x_{n}, \nabla g\left(x_{n}\right)-\lambda_{n} B x_{n}\right) \\
& \leq V\left(x_{n},\left[\nabla g\left(x_{n}\right)-\lambda_{n} B x_{n}\right]+\lambda_{n} B x_{n}\right)-\left\langle\nabla g^{*}\left[\nabla g\left(x_{n}\right)-\lambda_{n} B x_{n}\right]-x_{n}, \lambda_{n} B x_{n}\right\rangle \\
& =D\left(x_{n}, x_{n}\right)-\left\langle t_{n}-x_{n}, \lambda_{n} B x_{n}\right\rangle \\
& =-\left\langle t_{n}-x_{n}, \lambda_{n} B x_{n}\right\rangle \\
& \leq \frac{1}{c} \lambda_{n}^{2}\left\|B x_{n}-B p\right\|^{2} \\
& \leq \frac{\lambda_{n}^{2}}{c \alpha^{2}}\left\|x_{n}-p\right\|^{2} \\
& \leq \frac{b^{2}}{c \alpha^{2}}\left(\left\|x_{n}-u_{n}\right\|+\left\|u_{n}-p\right\|\right)^{2} \rightarrow 0(n \rightarrow \infty) .
\end{aligned}
$$

So, from Lemma 2.9, we have $\lim _{n \rightarrow \infty} D\left(x_{n}, \operatorname{Proj}_{C}^{g}\left(t_{n}\right)\right)=0$ which implies that

$$
\lim _{n \rightarrow \infty}\left\|x_{n}-\operatorname{Proj}_{C}^{g}\left(t_{n}\right)\right\|=0
$$

Thus, by the uniform continuity on any bounded set of $\nabla g(\cdot)$, we obtain that

$$
\lim _{n \rightarrow \infty}\left\|\nabla g\left(x_{n}\right)-\nabla g\left[\operatorname{Proj}_{C}^{g}\left(t_{n}\right)\right]\right\|=0 .
$$


(d) Now we prove that $p \in V I(C, B)$. Define $M: E \rightarrow 2^{E^{*}}$ as follows:

$$
M v= \begin{cases}B v+N_{C}(v), & v \in C, \\ \emptyset, & v \notin C,\end{cases}
$$

where $N_{C}(v)=\{w \in E:\langle v-u, w\rangle \geq 0, \forall u \in C\}$ is the normal cone to $C$ at $v \in C$. Then the multivalued mapping $M$ is maximal monotone and $M^{-1} 0=V I(C, B)$. Let $G(M)$ denote the graph of $M$ and let $(v, w) \in G(M)$, then we have $w \in M v=B v+N_{C}(v)$ and hence $w-B v \in N_{C}(v)$. Therefore, by $\operatorname{Proj}_{C}^{g}\left(t_{n}\right) \in C$, we have

$$
\left\langle v-\operatorname{Proj}_{C}^{g}\left(t_{n}\right), w-B v\right\rangle \geq 0 .
$$

On the other hand, it follows from Lemma 2.10 that

$$
\left\langle v-\operatorname{Proj}_{C}^{g}\left(t_{n}\right), \nabla g\left(\operatorname{Proj}_{C}^{g}\left(t_{n}\right)\right)-\nabla g\left(t_{n}\right)\right\rangle \geq 0 .
$$

That is,

$$
\left\langle v-\operatorname{Proj}_{C}^{g}\left(t_{n}\right), \frac{\nabla g\left(x_{n}\right)-\nabla g\left(\operatorname{Proj}_{C}^{g}\left(t_{n}\right)\right)}{\lambda_{n}}-B x_{n}\right\rangle \leq 0 .
$$

It follows from 3.24 and 3.25 that

$$
\begin{aligned}
\left\langle v-\operatorname{Proj}_{C}^{g}\left(t_{n}\right), w\right\rangle \geq & \left\langle v-\operatorname{Proj}_{C}^{g}\left(t_{n}\right), B v\right\rangle \\
\geq & \left\langle v-\operatorname{Proj}_{C}^{g}\left(t_{n}\right), B v\right\rangle+\left\langle v-\operatorname{Proj}_{C}^{g}\left(t_{n}\right), \frac{\nabla g\left(x_{n}\right)-\nabla g\left[\operatorname{Proj}_{C}^{g}\left(t_{n}\right)\right]}{\lambda_{n}}-B x_{n}\right\rangle \\
= & \left\langle v-\operatorname{Proj}_{C}^{g}\left(t_{n}\right), B v-B\left(\operatorname{Proj}_{C}^{g}\left(t_{n}\right)\right)\right\rangle+\left\langle v-\operatorname{Proj}_{C}^{g}\left(t_{n}\right), B\left(\operatorname{Proj}_{C}^{g}\left(t_{n}\right)\right)\right. \\
& \left.-B x_{n}\right\rangle+\left\langle v-\operatorname{Proj}_{C}^{g}\left(t_{n}\right), \frac{\nabla g\left(x_{n}\right)-\nabla g\left[\operatorname{Proj}_{C}^{g}\left(t_{n}\right)\right]}{\lambda_{n}}\right\rangle \\
\geq & -\left\|v-\operatorname{Proj}_{C}^{g}\left(t_{n}\right)\right\| \cdot \frac{\left\|\operatorname{Proj}_{C}^{g}\left(t_{n}\right)-x_{n}\right\|}{\alpha}-\left\|v-\operatorname{Proj}_{C}^{g}\left(t_{n}\right)\right\| \\
& \cdot \frac{\left\|\nabla g\left[\operatorname{Proj}_{C}^{g}\left(t_{n}\right)\right]-\nabla g\left(x_{n}\right)\right\|}{a} \\
\geq & -L\left(\frac{\left\|\operatorname{Proj}_{C}^{g}\left(t_{n}\right)-x_{n}\right\|}{\alpha}+\frac{\left\|\nabla g\left[\operatorname{Proj}_{C}^{g}\left(t_{n}\right)\right]-\nabla g\left(x_{n}\right)\right\|}{a}\right),
\end{aligned}
$$

where $L=\sup \left\{\left\|v-\operatorname{Proj}_{C}^{g}\left(t_{n}\right)\right\|: n \in N\right\}$, letting $n=n_{k}$ and $k \rightarrow+\infty$, using (3.9), (3.10), (3.22), and $(3.23)$, we obtain that $\langle v-p, w\rangle \geq 0$. Since $M$ is maximal monotone, we have $p \in M^{-1} 0$ and hence $p \in V I(C, B)$. Thus we have $p \in F$.

Step 6 Finally, we prove that $p=\operatorname{Proj}_{F}^{g}\left(x_{0}\right)$.

From $x_{n}=\operatorname{Proj}_{C_{n}}^{g}\left(x_{0}\right)$ and Lemma 2.10 , we see that $\left\langle x_{n}-z, \nabla g\left(x_{0}\right)-\nabla g\left(x_{n}\right)\right\rangle \geq 0$, for all $z \in C_{n}$. Since $F \subset C_{n}$ for each $n \geq 0$, we have $\left\langle x_{n}-w, \nabla g\left(x_{0}\right)-\nabla g\left(x_{n}\right)\right\rangle \geq 0$, for all $w \in F$. Let $n \rightarrow+\infty$ in the last inequality, we see that $\left\langle p-w, \nabla g\left(x_{0}\right)-\nabla g(p)\right\rangle \geq 0$, for all $w \in F$. In view of Lemma 2.10, we can obtain that $p=\operatorname{Proj}_{F}^{g} x_{0}$. This completes the proof of Theorem 3.1 .

\section{Remark 3.2 .}

(1) If we suppose that $T_{i}$ is uniformly $L_{i}$-Lipschitz continuous on $C$ for each $i \in N^{+}$, then the assumption that $T_{i}$ is closed and uniformly asymptotic regular on $C$ can be removed in Theorem 3.1 .

(2) Theorem 3.1 extends the mapping in Theorem 5.2 of Naraghirad and Yao [22] from a family of Bregman weak relatively nonexpansive mappings to a countable family of Bregman totally quasi$D$-asymptotically nonexpansive mappings. Meanwhile, Theorem 3.1 also removes the assumption $\widehat{F}(T)=F(T)$ on the mapping $T$. If we set $\lambda_{n} \equiv \lambda, \alpha_{n} \equiv 1, \zeta_{n} \equiv 0, r_{k, n} \equiv r_{n}, \varphi_{k}=A_{k} \equiv 0$, $k=m=1$, for all $n \in N$ in (3.1), then (3.1) can be rewritten as (1.5). Hence, Theorem 3.1 improves and extends Theorem 5.2 of Naraghirad and Yao [22]. 
(3) Theorem 3.1 also improves and generalizes Corollary 7 and Corollary 8 of Reich and Sabach [28], Theorem 12 of Zhu et al. [46], Theorem 20 of Pang and Naraghirad [24, Theorem 3.1 of Agarwal et al. [1], Theorem 2.1 of $\mathrm{Wu}$ and $\mathrm{Lv}$ [37, and others.

(4) For any positive integer $i$, let $R_{i}$ be a maximal monotone operator from $E$ to $E^{*}$ such that $R_{i}^{-1} 0 \neq \emptyset$. Let $r_{i}>0$ and $\operatorname{Res}_{r_{i}, R_{i}}^{g}=\left(\nabla g+r_{i} R_{i}\right)^{-1} \nabla g$ be the $g$-resolvent of $R_{i}$. Letting $T_{i}=\operatorname{Res}_{r_{i}, R_{i}}^{g}$. In view of Lemma 3.2 in [30, we may conclude that $T_{i}$ is a closed and Bregman relatively nonexpansive mapping and $\widetilde{F}\left(\operatorname{Res}_{r_{i}, R_{i}}^{g}\right)=F\left(\operatorname{Res}_{r_{i}, R_{i}}^{g}\right)=R_{i}^{-1}(0)$, so $T_{i}$ is a closed Bregman totally quasi- $D$-asymptotically nonexpansive mapping. Thus, if we take $T_{i}=\operatorname{Res}_{r_{i}, R_{i}}^{g}$ in Theorem 3.1. then we can obtain an algorithm for finding common zeroes of finitely many maximal monotone operators, here is omitted.

The space in Theorem 3.1 can be applicable to $E=L_{p}\left(l_{p}, W_{m}^{p}\right.$, respectively, where $\left.p \in(1,2]\right)$ and $g(x)=\|x\|^{2}$ for every $x \in E$ or $E=H$, etc.. Now, we give the following Example 3.3 in order to support Theorem 3.1. Meanwhile, Example 3.3 also shows that there is a countable family of closed, uniformly asymptotic regular and uniformly Bregman totally quasi- $D$-asymptotically nonexpansive mappings which are not Bregman $D$-nonexpansive mappings.

Example 3.3. Let $E=l^{2}$ and $C=\left\{x \in l^{2} \mid\|x\| \leq 1\right\}$, where $l^{2}=\left\{\sigma=\left.\left(\sigma_{1}, \sigma_{2}, \cdots, \sigma_{n}, \cdots\right)\left|, \sum_{n=1}^{+\infty}\right| \sigma_{n}\right|^{2}<\right.$ $+\infty\},\|\sigma\|=\left(\sum_{n=1}^{+\infty}\left|\sigma_{n}\right|^{2}\right)^{\frac{1}{2}}$ for all $\sigma=\left(\sigma_{1}, \sigma_{2}, \cdots, \sigma_{n}, \cdots\right) \in l^{2},\langle\sigma, \eta\rangle=\sum_{n=1}^{+\infty} \sigma_{n} \eta_{n}$ for all $\sigma=$ $\left(\sigma_{1}, \sigma_{2}, \cdots, \sigma_{n}, \cdots\right)$, and $\eta=\left(\eta_{1}, \eta_{2}, \cdots, \eta_{n}, \cdots\right) \in l^{2}$. Set $x_{0}=(1,0,0, \cdots)$, then $x_{0} \in C$ and $\left\|x_{0}\right\|=1$. Define the following countable family of mappings $T_{i}: C \rightarrow C$ by

$$
T_{i}\left(x_{1}, x_{2}, x_{3}, \cdots\right)=\left\{\begin{array}{l}
\left(0, x_{1}^{2}, a_{2} x_{2}, a_{3} x_{3}, \cdots\right), \text { if } x \in\left\{x=\left(x_{1}, x_{2}, x_{3}, \cdots\right) \mid x=\frac{x_{0}}{2^{n}} \in C\right\} \triangleq Q, \\
-\frac{1}{i+2}\left(x_{1}, x_{2}, x_{3}, \cdots\right), \text { if } x \in\left\{x=\left(x_{1}, x_{2}, x_{3}, \cdots\right) \mid x \in C \text { and } x \neq \frac{x_{0}}{2^{n}}\right\}
\end{array}\right.
$$

for all $i \in N$ and $n \geq 1, n \in N$, where $\left\{a_{i}\right\}$ is a sequence in $(0,1)$ such that $\Pi_{i=2}^{+\infty} a_{i}=\frac{1}{2}$.

It is proved in Goebel and Kirk [1] that

(i) $\left\|T_{i} x-T_{i} y\right\| \leq 2\|x-y\| \quad \forall x, y \in Q, i \in N$;

(ii) $\left\|T_{i}^{n} x-T_{i}^{n} y\right\| \leq\left(2 \Pi_{j=2}^{n} a_{j}\right)\|x-y\| \forall x, y \in Q, \forall n \geq 2, i \in N$.

It is clear that $F\left(T_{i}\right)=\{0\}$ for all $i \in N, E$ is a Hilbert space. Let $g: E \rightarrow R$ be defined by $g(x)=\|x\|^{2}$, $x \in E$, then the Bregman distance $D(x, y)=\|x-y\|^{2}$ for all $x, y \in E$.

Let $\zeta(t)=t$ for all $t \geq 0$, and $\left\{\mu_{n}\right\}$ be a nonnegative real sequence with $\mu_{n} \rightarrow 0$ as $n \rightarrow+\infty$. For any $p \in F\left(T_{i}\right)=\{0\}$ and $x \in C$, we consider the following two cases:

1) If $x \in Q$, then from (i) and (ii), we have

$$
\begin{aligned}
D\left(p, T_{i}^{n} x\right) & =\left\|p-T_{i}^{n} x\right\|^{2}=\left\|0-T_{i}^{n} x\right\|^{2}=\left\|T_{i}^{n} 0-T_{i}^{n} x\right\|^{2} \leq\left(2 \Pi_{j=2}^{n} a_{j}\right)^{2}\|0-x\|^{2} \\
& =\|x\|^{2}+\left[\left(2 \Pi_{j=2}^{n} a_{j}\right)^{2}-1\right] \cdot\|x\|^{2}=D(0, x)+\left[\left(2 \Pi_{j=2}^{n} a_{j}\right)^{2}-1\right] \cdot D(0, x) \\
& \leq D(p, x)+\left[\left(2 \Pi_{j=2}^{n} a_{j}\right)^{2}-1\right] \cdot \zeta(D(p, x))+\mu_{n}
\end{aligned}
$$

2) If $x \in C \backslash Q$, then $x \neq \frac{x_{0}}{2^{n}}, x \in C$ and $T_{i}^{n} x=\frac{(-1)^{n}}{(i+2)^{n}} x$, we have

$$
\begin{aligned}
D\left(p, T_{i}^{n} x\right) & =\left\|p-T_{i}^{n} x\right\|^{2}=\left\|0-T_{i}^{n} x\right\|^{2}=\left\|T_{i}^{n} x\right\|^{2}=\frac{1}{(i+2)^{2 n}}\|x\|^{2} \\
& \leq\|0-x\|^{2}+\frac{1}{(i+2)^{2 n}}\|0-x\|^{2}+\mu_{n}=D(p, x)+\frac{1}{(i+2)^{2 n}} D(p, x)+\mu_{n} \\
& =D(p, x)+\frac{1}{(i+2)^{2 n}} \zeta(D(p, x))+\mu_{n} .
\end{aligned}
$$


It follows from 1) and 2) that

$$
D\left(p, T_{i}^{n} x\right) \leq D(p, x)+\nu_{n}^{(i)} \cdot \zeta(D(p, x))+\mu_{n}^{(i)} \forall p \in F(T), x \in C, n \geq 1, i \geq 0,
$$

where $\nu_{n}^{(i)}=\max \left\{\left(2 \Pi_{j=2}^{n} a_{j}\right)^{2}-1, \frac{1}{(i+2)^{2 n}}\right\}$ and $\mu_{n}^{(i)}=\mu_{n}$.

Note that

$$
0 \leq \lim _{n \rightarrow+\infty} \sup _{i \geq 0}\left\{\nu_{n}^{(i)}\right\} \leq \lim _{n \rightarrow+\infty} \max \left\{\left(2 \Pi_{j=2}^{n} a_{j}\right)^{2}-1, \frac{1}{2^{2 n}}\right\}=0,
$$

thus we have $\lim _{n \rightarrow+\infty} \sup _{i \geq 0}\left\{\nu_{n}^{(i)}\right\}=0$. This implies that $T_{i}: C \rightarrow C$ is a countable family of uniformly Bregman totally quasi- $D$-asymptotically nonexpansive mappings for every $i \in N$. Next, we claim that $T_{i}$ is not a Bregman $D$-nonexpansive mapping for all $i \in N$. Indeed, let $s=\frac{3 x_{0}}{5}, t=\frac{x_{0}}{2} \in C$, then

$$
\begin{aligned}
D\left(T_{i} s, T_{i} t\right) & =\left\|T_{i} s-T_{i} t\right\|^{2}=\left\|\left(-\frac{1}{i+2}\right)\left(\frac{3}{5}, 0,0, \cdots\right)-\left(0, \frac{1}{4}, 0, \cdots\right)\right\|^{2} \\
& =\frac{9}{25(i+2)^{2}}+\frac{1}{16}>\left(\frac{1}{10}\right)^{2}=\left\|\frac{3 x_{0}}{5}-\frac{x_{0}}{2}\right\|^{2}=\|s-t\|^{2}=D(s, t)
\end{aligned}
$$

for all $i \in N$.

Now, if $x \in Q$, then $T_{i}^{m} x=\frac{1}{2^{2 n}}\left(\Pi_{j=2}^{m} a_{j}\right) \cdot(\underbrace{0, \cdots, 0}_{m}, 1,0, \cdots)$ for all $i \in N$ and $m \geq 2, m \in N$. For any bounded subset $K$ of $C$, we have

$$
\begin{aligned}
0 & \leq \lim _{n \rightarrow+\infty} \sup _{y \in K}\left\|T_{i}^{n+1} y-T_{i}^{n} y\right\| \\
\leq & \lim _{n \rightarrow+\infty} \max \left(\left\|\frac{1}{2^{2 n}}\left(\Pi_{j=2}^{n+1} a_{j}\right) \cdot(\underbrace{0, \cdots, 0}_{n+1}, 1,0, \cdots)-\frac{1}{2^{2 n}}\left(\Pi_{j=2}^{n} a_{j}\right) \cdot(\underbrace{0, \cdots, 0}_{n}, 1,0, \cdots)\right\|,\right. \\
& \left.\sup _{y \in K \backslash\left\{\frac{x_{0}}{2^{n}}\right\}}\left\|\frac{(-1)^{n+1}}{(i+2)^{n+1}} y-\frac{(-1)^{n}}{(i+2)^{n}} y\right\|\right) \\
\leq & \lim _{n \rightarrow+\infty} \max \left(\frac{1}{2^{2 n}}\left(\Pi_{j=2}^{n} a_{j}\right) \cdot \sqrt{a_{n+1}^{2}+1}, \sup _{y \in C \backslash\left\{\frac{x_{0}}{2^{n}}\right\}} \frac{i+3}{(i+2)^{n+1}}\|y\|\right) \\
\leq & \lim _{n \rightarrow+\infty} \max \left(\frac{\sqrt{1^{2}+1}}{2^{2 n}}\left(\Pi_{j=2}^{n} a_{j}\right), \frac{i+3}{(i+2)^{n+1}} \cdot 1\right) \\
\leq & \lim _{n \rightarrow+\infty} \max \left(\frac{\Pi_{j=2}^{n} a_{j}}{2^{2 n-0.5}}, \frac{2 i+4}{(i+2)^{n+1}}\right) \\
\leq & \lim _{n \rightarrow+\infty} \max \left(\frac{1}{2^{2 n-0.5}}, \frac{2}{(i+2)^{n}}\right) \\
\leq & \lim _{n \rightarrow+\infty} \max \left(\frac{1}{2^{2 n-0.5}}, \frac{1}{2^{n-1}}\right)=\lim _{n \rightarrow+\infty} \frac{1}{2^{n-1}}=0 .
\end{aligned}
$$

This implies that $\lim _{n \rightarrow+\infty} \sup _{y \in K}\left\|T_{i}^{n+1} y-T_{i}^{n} y\right\|=0$, that is, $T_{i}$ is uniformly asymptotically regular on $C$ for all $i \in N$.

For any sequence $\left\{y_{n}\right\} \subseteq C$ such that $\lim _{n \rightarrow+\infty} y_{n}=x^{0}$ and $\lim _{n \rightarrow+\infty} T_{i} y_{n}=y^{0}$, we consider the following two cases:

1) If the sequence $y_{n}=\frac{x_{0}}{2^{n}}$ and $\lim _{n \rightarrow+\infty} y_{n}=x^{0}$, then we have that $x^{0}=0$ and

$$
\begin{aligned}
0 & =\lim _{n \rightarrow+\infty}\left\|T_{i} y_{n}-y^{0}\right\|=\lim _{n \rightarrow+\infty}\left\|\left(0, \frac{1}{2^{2 n}}, 0, \cdots\right)-y^{0}\right\| \\
& \geq \limsup _{n \rightarrow+\infty}\left|\left\|y^{0}\right\|-\frac{1}{2^{2 n}}\right|=\left\|y^{0}\right\| \geq 0,
\end{aligned}
$$

this implies that $y^{0}=0$ and $T_{i} x^{0}=-\frac{x^{0}}{i+2}=0=y^{0}$. 
2) If $y_{n} \neq \frac{x_{0}}{2^{n}}, y_{n} \in C$ and $\lim _{n \rightarrow+\infty} y_{n}=x^{0}$, then it follows from

$$
\begin{aligned}
0 & =\lim _{n \rightarrow+\infty}\left\|T_{i} y_{n}-y^{0}\right\|=\lim _{n \rightarrow+\infty}\left\|-\frac{1}{i+2} y_{n}-y^{0}\right\|=\lim _{n \rightarrow+\infty}\left\|-\frac{1}{i+2}\left(y_{n}-x^{0}\right)-\left(y^{0}+\frac{x^{0}}{i+2}\right)\right\| \\
& \geq \limsup _{n \rightarrow+\infty}\left\|y^{0}+\frac{x^{0}}{i+2}\right\|-\left\|\frac{y_{n}-x^{0}}{i+2}\right\|\|=\| y^{0}+\frac{x^{0}}{i+2} \| \geq 0
\end{aligned}
$$

that $y^{0}=-\frac{x^{0}}{i+2}$, hence $T_{i} x^{0}=-\frac{1}{i+2} x^{0}=y^{0}$.

In summary, we can obtain that the map $T_{i}$ is closed for every $i \in N$.

Choose $i \in N$, for any $n \geq 1$ and $n \in N$, we may set $x_{n}=\frac{x_{0}}{2^{n+1}}$, then $x_{n} \in C$ and $x_{n} \rightarrow 0 \in F\left(T_{i}\right)=\{0\}$ as $n \rightarrow+\infty$.

Finally, it is obvious that the family $\left\{T_{i}\right\}_{i \in N}$ satisfies all the aspects of the hypothesis of Theorem 3.1 .

The following Example 3.4 shows that there is a Bregman totally quasi- $D$-asymptotically nonexpansive mapping $T$ which is not a Bregman $D$-nonexpansive mapping, but $T$ is both Bregman relatively nonexpansive and Bregman quasi-nonexpansive.

Example 3.4. Let $E=l^{2}, C=\left\{x \in l^{2} \mid\|x\| \leq 1\right\}$ and $g(x)=\|x\|^{2}$, where $l^{2}=\left\{\sigma=\left(\sigma_{1}, \sigma_{2}, \cdots, \sigma_{n}, \cdots\right) \mid\right.$ $\left.\sum_{n=1}^{+\infty}\left|\sigma_{n}\right|^{2}<+\infty\right\}$. $\|\sigma\|=\left(\sum_{n=1}^{+\infty}\left|\sigma_{n}\right|^{2}\right)^{\frac{1}{2}}$ for all $\sigma=\left(\sigma_{1}, \sigma_{2}, \cdots, \sigma_{n}, \cdots\right) \in l^{2} ;\langle\sigma, \eta\rangle=\sum_{n=1}^{+\infty} \sigma_{n} \eta_{n}$ for all $\sigma=\left(\sigma_{1}, \sigma_{2}, \cdots, \sigma_{n}, \cdots\right), \eta=\left(\eta_{1}, \eta_{2}, \cdots, \eta_{n}, \cdots\right) \in l^{2}$.

Let $T: C \rightarrow C$ be a mapping defined by

$$
T\left(x_{1}, x_{2}, x_{3}, \cdots\right)=\left(0, x_{1}^{2}, a_{2} x_{2}, a_{3} x_{3}, \cdots\right) \quad \forall\left(x_{1}, x_{2}, x_{3}, \cdots\right) \in C,
$$

where $\left\{a_{i}\right\}$ is a sequence in $(0,1)$ such that $\Pi_{i=2}^{+\infty} a_{i}=\frac{1}{2}$. Let $g: E \rightarrow R$ be defined by $g(x)=\|x\|^{2}, x \in E$, then the Bregman distance

$$
D(x, y)=g(x)-g(y)-\langle\nabla g(y), x-y\rangle=\|x\|^{2}-\|y\|^{2}-\langle 2 y, x-y\rangle=\|x-y\|^{2} \forall x, y \in C, F(T)=\{0\}(\neq \emptyset)
$$

and $E$ is a Hilbert space. It is proved in Goebel and Kirk [11]that

(i) $\|T x-T y\| \leq 2\|x-y\| \quad \forall x, y \in C$;

(ii) $\left\|T^{n} x-T^{n} y\right\| \leq\left(2 \Pi_{j=2}^{n} a_{j}\right)\|x-y\| \forall x, y \in C, \forall n \geq 2$.

Let $\zeta(t)=t$, for all $t \geq 0,\left\{\mu_{n}\right\}$ be a nonnegative real sequence with $\mu_{n} \rightarrow 0$ as $n \rightarrow+\infty$ and

$$
\nu_{n}= \begin{cases}3, & \text { if } n=1 \\ \left(2 \Pi_{j=2}^{n} a_{j}\right)^{2}-1, & \text { if } n \geq 2 \text { and } n \in N\end{cases}
$$

then from (i) and (ii), we have

$$
\left\|T^{n} x-T^{n} y\right\|^{2} \leq\|x-y\|^{2}+\nu_{n} \zeta\left(\|x-y\|^{2}\right)+\mu_{n} \forall x, y \in C, \forall n \geq 1,
$$

that is,

$$
D\left(T^{n} x, T^{n} y\right) \leq D(x, y)+\nu_{n} \zeta(D(x, y))+\mu_{n} \forall x, y \in C, \forall n \geq 1 .
$$

Let $x_{0}=(1,0,0, \cdots), y_{0}=\left(\frac{1}{2}, 0,0, \cdots\right) \in C$, then

$$
\begin{aligned}
D\left(T x_{0}, T y_{0}\right) & =\left\|T x_{0}-T y_{0}\right\|^{2}=\left\|\left(0,1^{2}, 0, \cdots\right)-\left(0, \frac{1}{4}, 0, \cdots\right)\right\|^{2}=\left(1-\frac{1}{4}\right)^{2}=\frac{9}{16} \\
& >\left\|x_{0}-y_{0}\right\|^{2}=\left\|(1,0,0, \cdots)-\left(\frac{1}{2}, 0,0, \cdots\right)\right\|^{2}=\left(1-\frac{1}{2}\right)^{2}=\frac{4}{16}=D\left(x_{0}, y_{0}\right)
\end{aligned}
$$


and

$$
\begin{aligned}
D(0, T x) & =\|0-T x\|^{2}=x_{1}^{4}+\Sigma_{i=2}^{+\infty} a_{i}^{2} x_{i}^{2} \leq x_{1}^{2}+\Sigma_{i=2}^{+\infty} x_{i}^{2} \\
& =\|x\|^{2}=\|0-x\|^{2}=D(0, x), \forall x=\left(x_{1}, x_{2}, x_{3}, \cdots\right) \in C .
\end{aligned}
$$

It is obvious that $F(T) \subset \hat{F}(T)$ for any mapping. Now, we show that $\hat{F}(T) \subset F(T)=\{0\}$. For any $p \in \hat{F}(T)$, then there exists a sequence $\left\{x_{n}\right\}$ in $C$ which converges weakly to $p$ and $\lim _{n \rightarrow+\infty}\left\|x_{n}-T x_{n}\right\|=0$. Setting $x_{n}=\left(x_{1}^{(n)}, x_{2}^{(n)}, x_{3}^{(n)}, \cdots\right)$, we have

$$
\begin{aligned}
\left\|x_{n}-T x_{n}\right\|^{2} & =\left\|\left(x_{1}^{(n)}, x_{2}^{(n)}, x_{3}^{(n)}, \cdots\right)-\left(0,\left(x_{1}^{(n)}\right)^{2}, a_{2} x_{2}^{(n)}, a_{3} x_{3}^{(n)}, \cdots\right)\right\|^{2} \\
& =\left(x_{1}^{(n)}\right)^{2}+\left[x_{2}^{(n)}-\left(x_{1}^{(n)}\right)^{2}\right]^{2}+\Sigma_{i=3}^{+\infty}\left(x_{i}^{(n)}-a_{i-1} x_{i-1}^{(n)}\right)^{2} \rightarrow 0 \text { as } n \rightarrow+\infty \\
& \Longleftrightarrow x_{i}^{(n)} \rightarrow 0 \text { as } n \rightarrow+\infty \text { for all } i \in N^{+} \Longleftrightarrow x_{n} \rightarrow 0 \text { as } n \rightarrow+\infty \\
& \Longrightarrow\left\{x_{n}\right\} \text { in } C \text { which converges weakly to } 0 .
\end{aligned}
$$

Thus, $p=0 \in F(T)$, from $\hat{F}(T)=F(T)=\{0\} \neq \emptyset$ and $(3.26)$, these imply that $T: C \rightarrow C$ is a Bregman relatively (asymptotically) nonexpansive nonlinear mapping.

These imply that $T$ is a Bregman totally $D$-asymptotically nonexpansive mapping with the nonempty fixed point set which is not a Bregman $D$-nonexpansive mapping. Hence, $T$ is a Bregman totally quasi$D$-asymptotically nonexpansive mapping which is not a Bregman $D$-nonexpansive mapping, but $T$ is both Bregman relatively nonexpansive and Bregman quasi-nonexpansive.

Setting $\zeta(t)=t, \nu_{n}^{(i)}=k_{n}^{(i)}-1, \lim _{n \rightarrow+\infty} \sup _{i \geq 0}\left\{k_{n}^{(i)}\right\}=1$, and $\mu_{n}^{(i)} \equiv 0$ for each $i \geq 0$ in Theorem 3.1 . we have the following Corollary 3.5 .

Corollary 3.5. Let $E$ be a 2-uniformly convex Banach space and $g: E \rightarrow R$ be a strongly coercive Bregman function which is bounded on bounded subsets and uniformly smooth and 2-uniformly convex on bounded subsets of $E$. Let $C$ be a nonempty, closed and convex subset of $E$. Suppose $B: C \rightarrow E^{*}$ is an $\alpha$ inverse-strongly monotone operator satisfying $(B 1)-(B 2)$. For each $k=1,2, \cdots, m$, let $A_{k}: C \rightarrow E^{*}$ be a continuous and monotone mapping, $\varphi_{k}: C \rightarrow R$ be a lower semicontinuous and convex functional, let $f_{k}: C \times C \rightarrow R$ be a bifunction satisfying $(C 1)-(C 4)$ and $T_{i}: C \rightarrow C \forall i \in N$ be an infinite family of closed and uniformly Bregman quasi-D-asymptotically nonexpansive mappings with nonnegative real sequences $\left\{k_{n}^{(i)}\right\} . \lim _{n \rightarrow+\infty} \sup _{i \geq 0}\left\{k_{n}^{(i)}\right\}=1, T_{0}=I$. Assume that $T_{i}$ is uniformly asymptotic regular on $C$ for all $i \geq 0$, i.e., $\lim _{n \rightarrow+\infty} \sup _{x \in K}\left\|T_{i}^{n+1} x-T_{i}^{n} x\right\|=0$ holds for any bounded subset $K$ of $C$ and $F=\left[\bigcap_{i=0}^{+\infty} F\left(T_{i}\right)\right] \cap\left[\bigcap_{k=1}^{m} \operatorname{GMEP}\left(f_{k}, \varphi_{k}\right)\right] \cap V I(C, B) \neq \emptyset$ for each $k=1,2, \cdots, m,\left\{r_{k, n}\right\}_{n=1}^{+\infty} \subset(0,+\infty)$ satisfying $\liminf _{n \rightarrow+\infty} r_{k, n}>0$ for all $z, y \in C, G_{k}(z, y)=f_{k}(z, y)+\varphi_{k}(y)-\varphi_{k}(z)+\left\langle A_{k} z, y-z\right\rangle$, $T_{r_{k, n}}^{G_{k}}(x)=\left\{z \in C: G_{k}(z, y)+\frac{1}{r_{k, n}}\langle y-z, \nabla g(z)-\nabla g(x)\rangle \geq 0, \forall y \in C\right\}$. Let $\left\{x_{n}\right\}$ be a sequence generated by

$$
\left\{\begin{array}{l}
x_{0} \in C \text { chosen arbitrarily, } \\
C_{0}=C \\
y_{n}=\nabla g^{*}\left\{\alpha_{n} \nabla g\left(\operatorname{Proj}_{C}^{g}\left[\nabla g^{*}\left(\nabla g\left(x_{n}\right)-\lambda_{n} B x_{n}\right)\right]\right)+\left(1-\alpha_{n}\right) \nabla g\left(z_{n}\right)\right\}, \\
z_{n}=\nabla g^{*}\left[\sum_{i=0}^{+\infty} \beta_{n}^{(i)} \nabla g\left(T_{i}^{n} x_{n}\right)\right], \\
u_{n}=T_{r_{m, n}}^{G_{m}} T_{r_{m-1, n}}^{G_{m-1}} \cdots T_{r_{2, n}}^{G_{2}} T_{r_{1, n}}^{G_{1}} y_{n}, \\
C_{n+1}=\left\{z \in C_{n}: D\left(z, u_{n}\right) \leq \alpha_{n} D\left(z, x_{n}\right)+\left(1-\alpha_{n}\right) D\left(z, z_{n}\right) \leq D\left(z, x_{n}\right)+\omega_{n}\right\}, \\
x_{n+1}=\operatorname{Proj}_{C_{n+1}}^{g}\left(x_{0}\right),
\end{array}\right.
$$


where $\omega_{n}=\sup _{i \geq 0}\left\{k_{n}^{(i)}-1\right\} \cdot \sup _{p \in F}\left\{D\left(p, x_{n}\right)\right\}<+\infty$ for each $n \geq 0,\left\{\lambda_{n}\right\} \subset[a, b]$ for some a,b with $0<$ $a<b<c \alpha$, where $\frac{1}{c}$ is 2-uniformly convexity constant of E satisfying Lemma $2.15(2),\left\{\alpha_{n}\right\},\left\{\beta_{n}^{(i)}\right\}(i \in N)$ are real sequences in $[0,1]$ satisfying the conditions:

$$
\forall n \geq 0, \sum_{i=0}^{\infty} \beta_{n}^{(i)}=1, \liminf _{n \rightarrow \infty}\left(1-\alpha_{n}\right) \beta_{n}^{(0)} \beta_{n}^{(i)}>0 \quad \forall i \in N .
$$

Then the sequence $\left\{x_{n}\right\}$ converges strongly to $\operatorname{Proj}_{F}^{g} x_{0}$.

Remark 3.6. Using Remark 3.2 (1), Corollary 3.5 improves and generalizes Theorem 3.4 of Chang et al. [9] in many aspects.

Setting $\nu_{n}^{(i)}=\mu_{n}^{(i)} \equiv 0$ for each $i \geq 0$ in Theorem 3.1, we have the following Corollary 3.7 .

Corollary 3.7. Let $E$ be a 2-uniformly convex Banach space and $g: E \rightarrow R$ be a strongly coercive Bregman function which is bounded on bounded subsets and uniformly smooth and 2-uniformly convex on bounded subsets of $E$. Let $C$ be a nonempty, closed and convex subset of $E$. Suppose $B: C \rightarrow E^{*}$ is an $\alpha$-inversestrongly monotone operator satisfying $(B 1)-(B 2)$. For each $k=1,2, \cdots, m$, let $A_{k}: C \rightarrow E^{*}$ be a continuous and monotone mapping, $\varphi_{k}: C \rightarrow R$ be a lower semicontinuous and convex functional, let $f_{k}: C \times C \rightarrow R$ be a bifunction satisfying $(C 1)-(C 4)$ and $T_{i}: C \rightarrow C$ for all $i \in N$ be an infinite family of closed and Bregman quasi-D-nonexpansive mappings and $T_{0}=I$. Assume that $F=\left[\bigcap_{i=0}^{+\infty} F\left(T_{i}\right)\right] \cap\left[\bigcap_{k=1}^{m} G M E P\left(f_{k}, \varphi_{k}\right)\right] \cap$ $V I(C, B) \neq \emptyset$. For each $k=1,2, \cdots, m,\left\{r_{k, n}\right\}_{n=1}^{+\infty} \subset(0,+\infty)$ satisfying $\liminf _{n \rightarrow+\infty} r_{k, n}>0$ for all $z, y \in C$,

$$
\begin{aligned}
& G_{k}(z, y)=f_{k}(z, y)+\varphi_{k}(y)-\varphi_{k}(z)+\left\langle A_{k} z, y-z\right\rangle, \\
& T_{r_{k, n}}^{G_{k}}(x)=\left\{z \in C: G_{k}(z, y)+\frac{1}{r_{k, n}}\langle y-z, \nabla g(z)-\nabla g(x)\rangle \geq 0, \forall y \in C\right\} .
\end{aligned}
$$

Let $\left\{x_{n}\right\}$ be a sequence generated by

$$
\left\{\begin{array}{l}
x_{0} \in C \text { chosen arbitrarily, } \\
C_{0}=C \\
y_{n}=\nabla g^{*}\left\{\alpha_{n} \nabla g\left(\operatorname{Proj}_{C}^{g}\left[\nabla g^{*}\left(\nabla g\left(x_{n}\right)-\lambda_{n} B x_{n}\right)\right]\right)+\left(1-\alpha_{n}\right) \nabla g\left(z_{n}\right)\right\} \\
z_{n}=\nabla g^{*}\left[\sum_{i=0}^{+\infty} \beta_{n}^{(i)} \nabla g\left(T_{i}^{n} x_{n}\right)\right] \\
u_{n}=T_{r_{m, n}}^{G_{m}} T_{r_{m-1, n}}^{G_{m-1}} \cdots T_{r_{2, n}}^{G_{2}} T_{r_{1, n}}^{G_{1}} y_{n} \\
C_{n+1}=\left\{z \in C_{n}: D\left(z, u_{n}\right) \leq \alpha_{n} D\left(z, x_{n}\right)+\left(1-\alpha_{n}\right) D\left(z, z_{n}\right) \leq D\left(z, x_{n}\right)\right\} \\
x_{n+1}=\operatorname{Proj}_{C_{n+1}}^{g}\left(x_{0}\right)
\end{array}\right.
$$

where $\left\{\lambda_{n}\right\} \subset[a, b]$ for some $a, b$ with $0<a<b<c \alpha$, where $\frac{1}{c}$ is 2-uniformly convexity constant of $E$ satisfying Lemma $2.15(2),\left\{\alpha_{n}\right\},\left\{\beta_{n}^{(i)}\right\}(i \in N)$ are real sequences in $[0,1]$ satisfying the conditions: $\forall n \geq 0$, $\sum_{i=0}^{\infty} \beta_{n}^{(i)}=1, \liminf _{n \rightarrow \infty}\left(1-\alpha_{n}\right) \beta_{n}^{(0)} \beta_{n}^{(i)}>0$ for all $i \in N$. Then the sequence $\left\{x_{n}\right\}$ converges strongly to $\operatorname{Proj}_{F}^{g} x_{0}$.

Remark 3.8. Using Remark 3.2 (1), Corollary 3.7 improves and generalizes Theorem 3.1 of Saewan and Kumam [33] in the following aspects:

(i) For the structure of Banach spaces, we extend the normalized duality mapping to a more general case, that is, a convex, continuous and strongly coercive Bregman function which is bounded on bounded subsets and uniformly convex and 2-uniformly smooth on bounded subsets. 
(ii) We extend the mapping from two relatively nonexpansive mappings to an infinite family of Bregman quasi- $D$-nonexpansive mappings, and the assumption $\widehat{F}(T)=F(T)$ on the mapping $T$ is removed.

(iii) For generalized mixed equilibrium problems, we extend the problems from one to a finite family.

Setting $g(x)=\|x\|^{2}$ in Theorem 3.1, we have the following Corollary 3.9 .

Corollary 3.9. Let $C$ be a nonempty, closed and convex subset of a 2-uniformly convex and uniformly smooth Banach space $E$. Suppose $B: C \rightarrow E^{*}$ is a $\alpha$-inverse-strongly monotone operator satisfying $(B 1)$ (B2). For each $k=1,2, \cdots, m$, let $A_{k}: C \rightarrow E^{*}$ be an continuous and monotone mapping, $\varphi_{k}: C \rightarrow R$ be a lower semicontinuous and convex functional, let $f_{k}: C \times C \rightarrow R$ be a bifunction satisfying $(C 1)-(C 4)$ and $T_{i}$ : $C \rightarrow C$ for all $i \in N$ be an infinite family of closed and uniformly totally quasi- $\phi$-asymptotically nonexpansive mappings with nonnegative real sequences $\left\{\nu_{n}^{(i)}\right\},\left\{\mu_{n}^{(i)}\right\}$ and a strictly increasing and continuous function $\zeta: R^{+} \rightarrow R^{+}$with $\zeta(0)=0 . \lim _{n \rightarrow+\infty} \sup _{i \geq 0}\left\{\nu_{n}^{(i)}\right\}=0$ and $\lim _{n \rightarrow+\infty} \sup _{i \geq 0}\left\{\mu_{n}^{(i)}\right\}=0, T_{0}=I$ and $I$ is the identity mapping on $C$. Assume that $F:=\left[\bigcap_{i=0}^{+\infty} F\left(T_{i}\right)\right] \cap\left[\bigcap_{k=1}^{m} \operatorname{GMEP}\left(f_{k}, \varphi_{k}\right)\right] \cap V I(C, B) \neq \emptyset$ and $T_{i}$ is uniformly asymptotic regular on $C$ for all $i \geq 0$, i.e., $\lim _{n \rightarrow+\infty} \sup _{x \in K}\left\|T_{i}^{n+1} x-T_{i}^{n} x\right\|=0$ holds for any bounded subset $K$ of $C$. For each $k=1,2, \cdots, m,\left\{r_{k, n}\right\}_{n=1}^{+\infty} \subset(0,+\infty)$ satisfying $\lim _{i n f} \rightarrow+\infty r_{k, n}>0$, for all $z, y \in C$,

$$
\begin{aligned}
& G_{k}(z, y)=f_{k}(z, y)+\varphi_{k}(y)-\varphi_{k}(z)+\left\langle A_{k} z, y-z\right\rangle, \\
& T_{r_{k, n}}^{G_{k}}(x)=\left\{z \in C: G_{k}(z, y)+\frac{1}{r_{k, n}}\langle y-z, J z-J x\rangle \geq 0, \forall y \in C\right\} .
\end{aligned}
$$

Let $\left\{x_{n}\right\}$ be a sequence generated by

$$
\left\{\begin{array}{l}
x_{0} \in C \text { chosen arbitrarily, } \\
C_{0}=C \\
y_{n}=J^{-1}\left\{\alpha_{n} J\left(\Pi_{C}\left[J^{-1}\left(J\left(x_{n}\right)-\lambda_{n} B x_{n}\right)\right]\right)+\left(1-\alpha_{n}\right) J\left(z_{n}\right)\right\}, \\
z_{n}=J^{-1}\left[\sum_{i=0}^{+\infty} \beta_{n}^{(i)} J\left(T_{i}^{n} x_{n}\right)\right], \\
u_{n}=T_{r_{m, n}}^{G_{m}} T_{r_{m-1, n}}^{G_{m-1}} \cdots T_{r_{2, n}}^{G_{2}} T_{r_{1, n}}^{G_{1}} y_{n}, \\
C_{n+1}=\left\{z \in C_{n}: \phi\left(z, u_{n}\right) \leq \alpha_{n} \phi\left(z, x_{n}\right)+\left(1-\alpha_{n}\right) \phi\left(z, z_{n}\right) \leq \phi\left(z, x_{n}\right)+\omega_{n}\right\} \\
x_{n+1}=\Pi_{C_{n+1}}\left(x_{0}\right),
\end{array}\right.
$$

where $\omega_{n}=\sup _{i \geq 0}\left\{\nu_{n}^{(i)}\right\} \cdot \sup _{p \in F}\left\{\zeta\left[\phi\left(p, x_{n}\right)\right]\right\}+\sup _{i \geq 0}\left\{\mu_{n}^{(i)}\right\}<+\infty$ for each $n \geq 0,\left\{\lambda_{n}\right\} \subset[a, b]$ for some $a, b$ with $0<a<b<c \alpha$, where $\frac{1}{c}$ is 2-uniformly convexity constant of $E .\left\{\alpha_{n}\right\},\left\{\beta_{n}^{(i)}\right\}(i \in N)$ are real sequences in $[0,1]$ satisfying the conditions: for all $n \geq 0, \sum_{i=0}^{\infty} \beta_{n}^{(i)}=1, \liminf _{n \rightarrow \infty}\left(1-\alpha_{n}\right) \beta_{n}^{(0)} \beta_{n}^{(i)}>0$ for all $i \in N$. Then the sequence $\left\{x_{n}\right\}$ converges strongly to $\Pi_{F} x_{0}$.

Setting $E=H$ in Theorem 3.1, we have the following Corollary 3.10 .

Corollary 3.10. Let $C$ be a nonempty, closed and convex subset of real Hilbert space E. Suppose $B: C \rightarrow E^{*}$ is an $\alpha$-inverse-strongly monotone operator satisfying $(B 1)-(B 2)$. For each $k=1,2, \cdots, m$, let $A_{k}: C \rightarrow E^{*}$ be a continuous and monotone mapping, $\varphi_{k}: C \rightarrow R$ be a lower semicontinuous and convex functional, let $f_{k}: C \times C \rightarrow R$ be a bifunction satisfying (C1)-(C4) and $T_{i}: C \rightarrow C$ for all $i \in N$ be an infinite family of closed and uniformly totally quasi-asymptotically nonexpansive mappings with nonnegative real sequences $\left\{\nu_{n}^{(i)}\right\},\left\{\mu_{n}^{(i)}\right\}$ and a strictly increasing and continuous function $\zeta: R^{+} \rightarrow R^{+}$with $\zeta(0)=0$. $\lim _{n \rightarrow+\infty} \sup _{i \geq 0}\left\{\nu_{n}^{(i)}\right\}=0$ and $\lim _{n \rightarrow+\infty} \sup _{i \geq 0}\left\{\mu_{n}^{(i)}\right\}=0, T_{0}=I$ and $I$ is the identity mapping on $C$. Assume that $F:=\left[\bigcap_{i=0}^{+\infty} F\left(T_{i}\right)\right] \cap\left[\bigcap_{k=1}^{m} \operatorname{GMEP}\left(f_{k}, \varphi_{k}\right)\right] \cap V I(C, B) \neq \emptyset$ and $T_{i}$ is uniformly asymptotic 
regular on $C$ for all $i \geq 0$, i.e., $\lim _{n \rightarrow+\infty} \sup _{x \in K}\left\|T_{i}^{n+1} x-T_{i}^{n} x\right\|=0$ holds for any bounded subset $K$ of $C$. For each $k=1,2, \cdots, m,\left\{r_{k, n}\right\}_{n=1}^{+\infty} \subset(0,+\infty)$ satisfying $\liminf _{n \rightarrow+\infty} r_{k, n}>0$, for all $z, y \in C$,

$$
\begin{aligned}
& G_{k}(z, y)=f_{k}(z, y)+\varphi_{k}(y)-\varphi_{k}(z)+\left\langle A_{k} z, y-z\right\rangle, \\
& T_{r_{k, n}}^{G_{k}}(x)=\left\{z \in C: G_{k}(z, y)+\frac{1}{r_{k, n}}\langle y-z, z-x\rangle \geq 0, \forall y \in C\right\} .
\end{aligned}
$$

Let $\left\{x_{n}\right\}$ be a sequence generated by

$$
\left\{\begin{aligned}
& x_{0} \in C \text { chosen arbitrarily, } \\
& C_{0}=C \\
& y_{n}= \alpha_{n} P_{C}\left(x_{n}-\lambda_{n} B x_{n}\right)+\left(1-\alpha_{n}\right) z_{n}, \\
& z_{n}= \sum_{i=0}^{+\infty} \beta_{n}^{(i)} T_{i}^{n} x_{n}, \\
& u_{n}= T_{r_{m, n}}^{G_{m}} T_{r_{m-1, n}}^{G_{m-1}} \cdots T_{r_{2, n}}^{G_{2}} T_{r_{1, n}}^{G_{1}} y_{n}, \\
& C_{n+1}=\left\{z \in C_{n}:\left\|z-u_{n}\right\|^{2} \leq \alpha_{n}\left\|z-x_{n}\right\|^{2}+\left(1-\alpha_{n}\right)\left\|z-z_{n}\right\|^{2} \leq\left\|z-x_{n}\right\|^{2}+\omega_{n}\right\}, \\
& x_{n+1}=P_{C_{n+1}}\left(x_{0}\right),
\end{aligned}\right.
$$

where $\omega_{n}=\sup _{i \geq 0}\left\{\nu_{n}^{(i)}\right\} \cdot \sup _{p \in F}\left\{\zeta\left(\left\|p-x_{n}\right\|^{2}\right)\right\}+\sup _{i \geq 0}\left\{\mu_{n}^{(i)}\right\}<+\infty$ for each $n \geq 0,\left\{\lambda_{n}\right\} \subset[a, b]$ for some $a, b$ with $0<a<b<\alpha .\left\{\alpha_{n}\right\},\left\{\beta_{n}^{(i)}\right\}(i \in N)$ are real sequences in [0,1] satisfying the conditions: for all $n \geq 0, \sum_{i=0}^{\infty} \beta_{n}^{(i)}=1, \liminf _{n \rightarrow \infty}\left(1-\alpha_{n}\right) \beta_{n}^{(0)} \beta_{n}^{(i)}>0$ for all $i \in N$. Then the sequence $\left\{x_{n}\right\}$ converges strongly to $P_{F} x_{0}$.

Remark 3.11. Corollary 3.10 improves and extends Theorem 2.1 of Martinez-Yanes and Xu [18] in the following aspects:

(1) From a nonexpansive mapping to a countable family of totally quasi-asymptotically nonexpansive mappings.

(2) Considering the generalized mixed equilibrium problems from zero to a finite family.

\section{Acknowledgment}

The research was partially supported by the National Natural Science Foundation of China (Grant No. 11671365).

\section{References}

[1] R. P. Agarwal, J. W. Chen, Y. J. Cho, Strong convergence theorems for equilibrium problems and weak Bregman relatively nonexpansive mappings in Banach spaces, J. Inequal. Appl., 2013 (2013), 16 pages. 1, 2.7, 2, 2.13, 3.2

[2] H. H. Bauschke, J. M. Borwein, P. L. Combettes, Bregman monotone optimization algorithms, SIAM J. Control Optim., 42 (2003), 596-636. 2.7.2

[3] H. H. Bauschke, P. L. Combettes, A weak-to-strong convergence principle for Fejér-monotone methods in Hilbert spaces, Math. Oper. Res., 26 (2001), 248-264. 1

[4] H. H. Bauschke, P. L. Combettes, Construction of best Bregman approximations in reflexive Banach spaces, Proc. Am. Math. Soc., 131 (2003), 3757-3766. 2

[5] J. M. Borwein, S. Reich, S. Sabach, A characterization of Bregman firmly nonexpansive operators using a new monotonicity concept, J. Nonlinear Convex Anal., 12 (2011), 161-184. 2.4, 2

[6] L. M. Bregman, The relaxation method of finding the common point of convex sets and its application to the solution of problems in convex programming, USSR Comput. Math. Math. Phys., 7 (1967), 200-217. 1. 2.1. 2.4. 2

[7] D. Butnariu, E. Resmerita, Bregman distances, totally convex functions, and a method for solving operator equations in Banach spaces, Abstr. Appl. Anal., 2006 (2006), 39 pages. 1, 2.1, 2.14 
[8] G. Cai, C. S. Hu, On the strong convergence of the implicit iterative processes for a finite family of relatively weak quasi-nonexpansive mappings, Appl. Math. Lett., 23 (2010), 73-78.

[9] S. S. Chang, L. Wang, X. R. Wang, C. K. Chan, Strong convergence theorems for Bregman totally quasiasymptotically nonexpansive mappings in reflexive Banach spaces, Appl. Math. Comput., 228 (2014), 38-48. 1. 2.6, 2.6, 2.8, 2, 3.6

[10] J. Chen, Z. Wan, L. Yuan, Y. Zheng, Approximation of fixed points of weak Bregman relatively nonexpansive mappings in Banach spaces, Int. J. Math. Math. Sci., 2011 (2011), 23 pages. 2

[11] K. Goebel, W. A. Kirk, A fixed point theorem for asymptotically nonexpansive mappings, Proc. Am. Math. Soc., 35 (1972), 171-174. 1, $1,3.3,3.4$

[12] B. Halpren, Fixed points of nonexpansive maps, Bull. Amer. Math. Soc., 73 (1967), 957-961. 1

[13] H. Iiduka, W. Takahashi, Strong convergence studied by a hybrid type method for monotone operators in a Banach space, Nonlinear Anal., 68 (2008), 3679-3688. 1, 1 ,

[14] H. Iiduka, W. Takahashi, Weak convergence of a projection algorithm for variational inequalities in a Banach space, J. Math. Anal. Appl., 339 (2008), 668-679. 1

[15] G. Kassay, S. Reich, S. Sabach, Iterative methods for solving systems of variational inequalities in reflexive Banach spaces, SIAM J. Optim., 21 (2011), 1319-1344. 1

[16] W. R. Mann, Mean value methods in iteration, Proc. Amer. Math. Soc., 4 (1953), 506-510. 1 2.4

[17] V. Martín-Márquez, S. Reich, S. Sabach, Right Bregman nonexpansive operators in Banach spaces, Nonlinear Anal., 75 (2012), 5448-5465. 2

[18] C. Martinez-Yanes, H. K. Xu, Strong convergence of the CQ method for fixed point iteration processes, Nonlinear Anal., 64 (2006), 2400-2411. 1, 1 , 3.11

[19] S.-Y. Matsushita, W. Takahashi, An iterative algorithm for relatively nonexpansive mappings by a hybrid method and applications, Nonlinear analysis and convex analysis, 305-313, Yokohama Publ., Yokohama, (2004). 1

[20] S.-Y. Matsushita, W. Takahashi, A strong convergence theorem for relatively nonexpansive mappings in a Banach space, J. Approx. Theory, 134 (2005), 257-266. 1

[21] E. Naraghirad, W. Takahashi, J. C. Yao, Generalized retraction and fixed point theorems using Bregman functions in Banach spaces, J. Nonlinear Convex Anal., 13 (2012), 141-156. 2.3, 2.7, 2

[22] E. Naraghirad, J. C. Yao, Bregman weak relatively nonexpansive mappings in Banach spaces, Fixed Point Theory Appl., 2013 (2013), 43 pages. 1, 1, 2.7, 2.8, 2.10, 2.12, 3.2

[23] R. X. Ni, J. C. Yao, The modified Ishikawa iterative algorithm with errors for a countable family of Bregman totally quasi-D-asymptotically nonexpansive mappings in reflexive Banach spaces, Fixed Point Theory Appl., 2015 (2015), 24 pages. 2.6. 2.11

[24] C. T. Pang, E. Naraghirad, Approximating common fixed points of Bregman weakly relatively nonexpansive mappings in Banach spaces, J. Funct. Spaces, 2014 (2014), 19 pages. 1, $2.7,3.2$

[25] C. T. Pang, E. Naraghirad, C. F. Wen, Weak convergence theorems for Bregman relatively nonexpansive mappings in Banach spaces, J. Appl. Math., 2014 (2014), 9 pages. 2.7, 2.14

[26] N. Petrot, K. Wattanawitoon, P. Kumam, A hybrid projection method for generalized mixed equilibrium problems and fixed point problems in Banach spaces, Nonlinear Anal. Hybrid Syst., 4 (2010), 631-643. 1 , 1

[27] X. Qin, Y. Su, Strong convergence theorems for relatively nonexpansive mappings in a Banach space, Nonlinear Anal., 67 (2007), 1958-1965. 1, 1 ,

[28] S. Reich, S. Sabach, Two strong convergence theorems for Bregman strongly nonexpansive operators in reflexive Banach spaces, Nonlinear Anal., 73 (2010), 122-135. 1, 2.5, 2, 2.7, 2.10, 3.2

[29] S. Reich, S. Sabach, Two strong convergence theorems for a proximal method in reflexive Banach spaces, Numer. Funct. Anal. Optim., 31 (2010), 22-44. 2.7, 2

[30] S. Reich, S. Sabach, A projection method for solving nonlinear problems in reflexive Banach spaces, J. Fixed Point Theory Appl., 9 (2011), 101-116. 3.2

[31] S. Reich, S. Sabach, Existence and approximation of fixed points of Bregman firmly nonexpansive mappings in reflexive Banach spaces, Fixed-point algorithms for inverse problems in science and engineering, 301-316, Springer Optim. Appl., 49, Springer, New York, (2011). 1, 2.2, $2,2.7$

[32] S. Sabach, Products of finitely many resolvents of maximal monotone mappings in reflexive Banach spaces, SIAM J. Optim., 21 (2011), 1289-1308. 2

[33] S. Saewan, P. Kumam, A hybrid iterative scheme for a maximal monotone operator and two countable families of relatively quasi-nonexpansive mappings for generalized mixed equilibrium and variational inequality problems, Abstr. Appl. Anal., 2010 (2010), 31 pages. 1, 1, 1, 2.7, 3.8

[34] S. Saewan, P. Kumam, K. Wattanawitoon, Convergence theorem based on a new hybrid projection method for finding a common solution of generalized equilibrium and variational inequality problems in Banach spaces, Abstr. Appl. Anal., 2010 (2010), 25 pages. 1, 1 ,

[35] S. Suantai, Y. J. Cho, P. Cholamjiak, Halpern's iteration for Bregman strongly nonexpansive mappings in reflexive Banach spaces, Comput. Math. Appl., 64 (2012), 489-499. 1], 2

[36] K. Wattanawitoon, P. Kumam, Generalized mixed equilibrium problems for maximal monotone operators and two relatively quasi-nonexpansive mappings, Thai J. Math., 9 (2011), 171-195. $1,1,2.7$

[37] C. Wu, S. Lv, Bregman projection methods for zeros of monotone operators, J. Fixed Point Theory, 2013 (2013), 
7 pages. $1,3.2$

[38] L. Yang, F. Zhao, J. K. Kim, Hybrid projection method for generalized mixed equilibrium problem and fixed point problem of infinite family of asymptotically quasi- $\phi$-nonexpansive mappings in Banach spaces, Appl. Math. Comput., 218 (2012), 6072-6082. 1, $1,2.6$

[39] Y. Yao, R. Chen, Y. C. Liou, A unified implicit algorithm for solving the triple-hierarchical constrained optimization problem, Math. Comput. Modelling, 55 (2012), 1506-1515.

[40] Y. Yao, Y. J. Cho, Y. C. Liou, Iterative algorithms for hierarchical fixed points problems and variational inequalities, Math. Comput. Modelling, 52 (2010), 1697-1705.

[41] Y. Yao, W. Jigang, Y. C. Liou, Regularized methods for the split feasibility problem, Abstr. Appl. Anal., 2012 (2012), 13 pages.

[42] Y. Yao, M. A. Noor, Y. C. Liou, S. M. Kang, Iterative algorithms for general multivalued variational inequalities, Abstr. Appl. Anal., 2012 (2012), 10 pages.

[43] Y. Yao, M. Postolache, Y. C. Liou, Z. Yao, Construction algorithms for a class of monotone variational inequalities, Optim. Lett., 10 (2016), 1519-1528. 1, 1

[44] C. Zălinescu, Convex analysis in general vector spaces, World Scientific Publishing Co., Inc., River Edge, NJ, (2002). 2, 2.15, 2.16

[45] J. Zhu, S. S. Chang, Halpern-Mann's iterations for Bregman strongly nonexpansive mappings in reflexive Banach spaces with applications, J. Inequal. Appl., 2013 (2013), 14 pages. 2.7. 2

[46] J. Zhu, S. S. Chang, M. Liu, Strong convergence theorem for Bregman strongly nonexpansive mappings and equilibrium problems in reflexive Banach spaces, J. Appl. Math., 2013 (2013), 7 pages. 1, 1, 2.7, 2, $2.9,3.2$

[47] H. Zhou, G. Gao, B. Tan, Convergence theorems of a modified hybrid algorithm for a family of quasi- $\phi$ asymptotically nonexpansive mappings, J. Appl. Math. Comput., 32 (2010), 453-464. 1, 1 , 2.6, 2.7 